\title{
Fault model of the 2012 doublet earthquake, near the up-dip end of the 2011 Tohoku-Oki earthquake, based on a near-field tsunami: implications for intraplate stress state
}

\author{
Tatsuya Kubota ${ }^{1,2^{*}}$, Ryota Hino², Daisuke Inazu ${ }^{3}$ and Syuichi Suzuki ${ }^{2}$
}

\begin{abstract}
On December 7, 2012, an earthquake occurred within the Pacific Plate near the Japan Trench, which was composed of deep reverse- and shallow normal-faulting subevents (Mw 7.2 and 7.1, respectively) with a time interval of $\sim 10 \mathrm{~s}$. It had been known that the stress state within the plate was characterized by shallow tensile and deep horizontal compressional stresses due to the bending of the plate (bending stress). This study estimates the fault model of the doublet earthquake utilizing tsunami, teleseismic, and aftershock data and discusses the stress state within the incoming plate and spatiotemporal changes seen in it after the 2011 Tohoku-Oki earthquake. We obtained the vertical extents of the fault planes of deep and shallow subevents as $\sim 45-70 \mathrm{~km}$ and $\sim 5$ (the seafloor) $-35 \mathrm{~km}$, respectively. The down-dip edge of the shallow normal-faulting seismic zone ( 30-35 km) deepened significantly compared to what it was in $2007(\sim 25 \mathrm{~km})$. However, a quantitative comparison of the brittle strength and bending stress suggested that the change in stress after the Tohoku-Oki earthquake was too small to deepen the down-dip end of the seismicity by $\sim 10 \mathrm{~km}$. To explain the seismicity that occurred at a depth of $\sim 30-35 \mathrm{~km}$, the frictional coefficient in the normal-faulting depth range required would have had to be $\sim 0.07 \leq$ $\mu \leq \sim 0.2$, which is significantly smaller than the typical friction coefficient. This suggests the infiltration of pore fluid along the bending faults, down to $\sim 30-35 \mathrm{~km}$. It is considered that the plate had already yielded to a depth of 35 $\mathrm{km}$ before 2011 and that the seismicity of the area was reactivated by the increase in stress from the Tohoku-Oki earthquake.
\end{abstract}

Keywords: Ocean bottom pressure gauge, Doublet earthquake, Intraplate earthquake, 2011 Tohoku-Oki earthquake, Bending stress, Fault modeling

\section{Introduction}

It is well known that the stress state within the incoming Pacific Plate near the Japan Trench is characterized by shallow tensile and deep horizontal compressional stresses along a direction perpendicular to the trench axis, separated by a thin aseismic (i.e., stress-neutral) "elastic core",

\footnotetext{
* Correspondence: kubotatsu@bosai.go.jp

${ }^{1}$ National Research Institute for Earth Science and Disaster Resilience, 3-1 Tennodai, Tsukuba, Ibaraki 305-0006, Japan

${ }^{2}$ Graduate School of Science, Tohoku University, 6-6 Aza-Aoba, Aramaki,

Aoba-ku, Sendai, Miyagi 980-8578, Japan

Full list of author information is available at the end of the article
}

due to the bending of the plate (bending stress, Fig. 1c; e.g., Chapple and Forsyth 1979). It is also well known that the number of normal-faulting earthquakes occurring within the plate and near the trench axis increases, following interplate megathrust earthquakes; this is attributed to the increased horizontal tensile stress caused by the stress release of the interplate coupling (e.g., Christensen and Ruff 1988; Dmowska and Lovison 1988).

Recently, Craig et al. (2014) investigated the vertical variation in the centroid depth and fault mechanisms based on global catalogs $(\mathrm{M}>\sim 5)$ and noted that temporal changes in the transition depths between normal- 


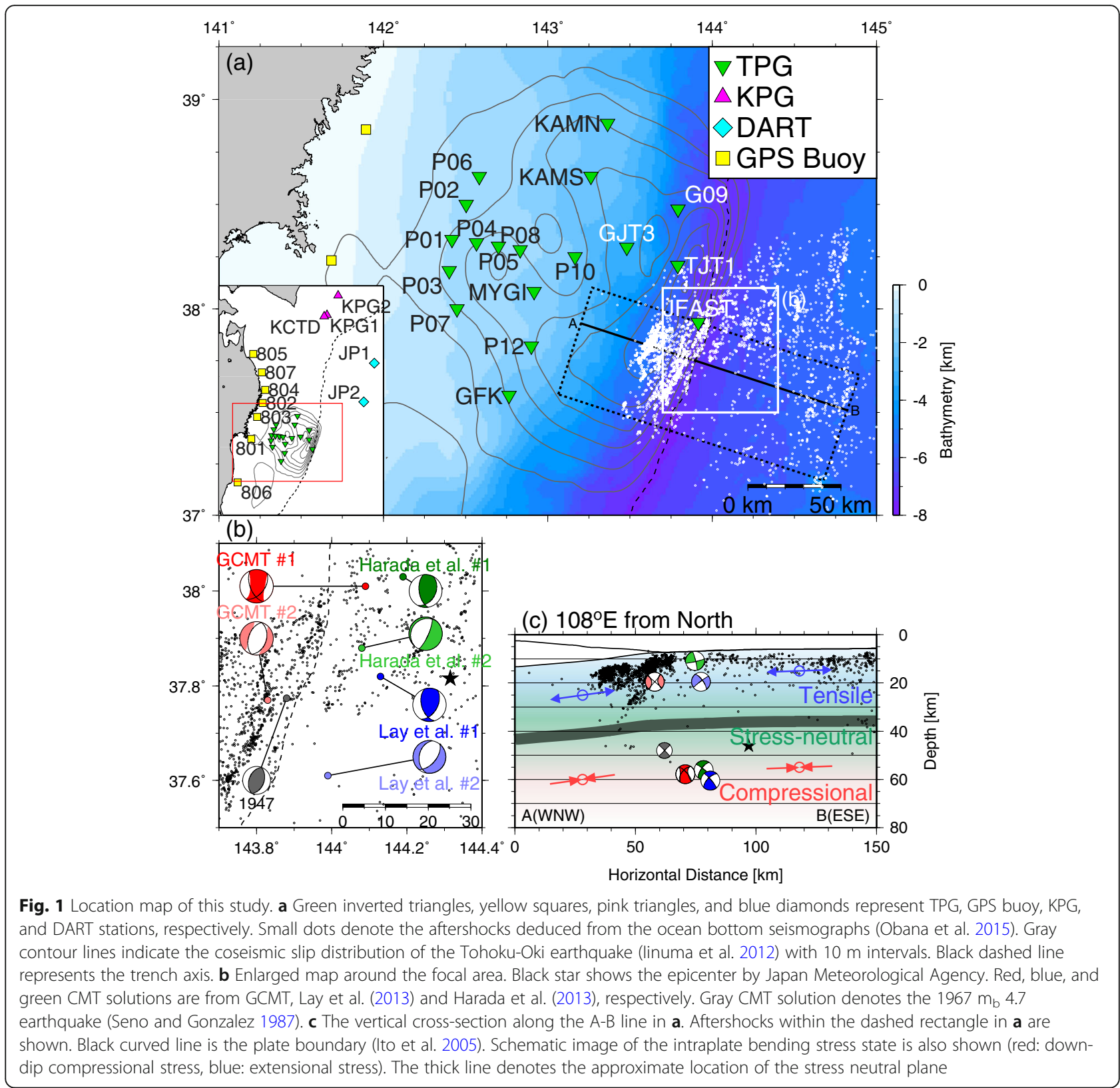

and reverse-faulting earthquakes were not detected after the 2011 Tohoku-Oki earthquake. However, Obana et al. (2012, 2014, 2015, 2019) studied ocean bottom seismographs and reported that the down-dip limit of shallow normal-faulting earthquakes $(\mathrm{M}<\sim 5)$ within the plate near the trench axis deepened from $\sim 25$ to $\sim 35 \mathrm{~km}$ after the same earthquake; they interpreted spatiotemporal change in the intraplate stress as having been caused by the release of stress associated with the Tohoku-Oki earthquake. However, the reason for this inconsistency has not been clarified. Furthermore, the relationship between the stress state in the incoming Pacific Plate and the changes in coseismic stress due to the Tohoku-Oki earthquake have not yet been quantitatively assessed in detail.

On December 7, 2012, an Mjma 7.3 earthquake occurred within the Pacific Plate near the Japan Trench, where the extremely large coseismic slip (> 50 m) was estimated to have occurred during the 2011 Tohoku-Oki earthquake (e.g., Iinuma et al. 2012; star in Fig. 1b). Detailed teleseismic analyses (Lay et al. 2013; Harada et al. 2013) revealed that this earthquake was composed of two $\mathrm{M} \sim 7$ subevents. According to the global centroid moment tensor (GCMT) solution (http://www.globalcmt.org/; Ekström et al. 2012), the first subevent had a reverse-faulting mechanism with a depth of $\sim 60 \mathrm{~km}$ (Mw 7.2) and the second had a normal- 
faulting mechanism $(\sim 20 \mathrm{~km}, \mathrm{Mw} 7.2)$ with a time interval of $\sim 12 \mathrm{~s}$ (red CMT solutions in Fig. 1b and c). Hereafter, this earthquake is referred to as the doublet earthquake, and the first and the second subevents are referred to as subevent 1 and subevent 2, respectively. Since the fault mechanisms of the two subevents are consistent with bending stress, the source process of the doublet earthquake should reflect the intraplate stress state after the Tohoku-Oki earthquake. The vertical extents of each fault will be key to discussing the temporal change in the vertical variations of the stress state after the 2011 Tohoku-Oki earthquake.

Rupture processes related to the doublet earthquake have been investigated previously. Lay et al. (2013) and Harada et al. (2013) investigated this earthquake using teleseismic data to estimate the CMT solution and the finite fault model. Teleseismic data is generally a powerful dataset for resolving rupture processes of global earthquakes. However, since the teleseismic signals from each subevent overlapped, it is difficult to decompose the rupture process of the doublet earthquake precisely, especially for the latter, shallower, subevent.

Inazu and Saito (2014) estimated the spatial distribution of the initial sea-surface height change (tsunami source) using far-field tsunami data from $\sim 200-2000 \mathrm{~km}$ away from the focal area (Additional file 1: Figure S1). In contrast to teleseismic data, tsunami data is useful for constraining the rupture process of the subevent 2 , since shallow earthquakes generally excite tsunamis or cause seafloor vertical deformation more effectively than deep earthquakes.

When the 2012 doublet earthquake occurred, off-line autonomous absolute ocean bottom pressure gauges (PGs) installed near the focal area $(<\sim 200 \mathrm{~km}$ from the source, Fig. 1a) recorded clear tsunami signals. This dataset is useful to constrain the fault model of subevent 2, which was difficult to constrain with teleseismic data. In the present study, we utilize the tsunami and aftershock data and the results of the teleseismic analysis to estimate the finite fault model of the 2012 doublet earthquake, focusing particularly on the vertical extent of the fault planes of each subevent. We also discuss the relationship between the vertical profile of the intraplate seismicity and its spatiotemporal changes associated with the 2011 Tohoku-Oki earthquake.

\section{Methods/Experimental}

\section{Tsunami data}

We use the near-field PGs installed by Tohoku University (hereafter TPG; e.g., Hino et al. 2014; Kubota et al. 2017a, 2017b) (green inverted triangles in Fig. 1a). We also use tsunami data obtained by the off-Kushiro online cabled PGs installed by Japan Agency for Marine-Earth Science and Technology (JAMSTEC) (Hirata et al. 2002) (KPGs, pink triangles), by GPS buoys installed by the Port and
Airport Research Institute (PARI) (Kato et al. 2005) (yellow squares), and by the Deep-ocean Assessment and Reporting of Tsunamis (DART) system (Bernard et al. 2014) (blue diamonds). Detailed information is given in Table 1.

To retrieve the tsunami waveforms, we remove the ocean-tide component using the theoretical tide model (Matsumoto et al. 2000) and apply the filter from Saito (1978). The lowpass filter we applied has a cutoff of 3 min to the TPG records, and the bandpass filter has a passband of 3-60 min to the KPG, GPS buoy, and DART records. We apply the lowpass filter to the TPG records to preserve the offset in the pressure change caused by the vertical deformation of the seafloor.

The filtered records are shown in Fig. 2. TPGs first capture down-motion tsunamis with amplitudes of $\sim-5 \mathrm{~cm}$ and then larger up-motion tsunamis with amplitudes of $\sim+10 \mathrm{~cm}$. The durations of both the down- and up-motion tsunamis are $\sim 5$ min (black dashed lines in Fig. 2a). Small fluctuations and changes in the pressure offset are observed at the stations near the focal area (Fig. 2b). Tsunami amplitudes at the DART and the KPG stations are very small $(\sim 1$ $\mathrm{cm}$, black dashed lines in Fig. 2c and d). At the former, dynamic pressure changes caused by seismic waves (e.g., Kubota et al. 2017b) are also observed. Tsunami signals are also detected by some GPS buoys (e.g., $\sim 15 \mathrm{~cm}$ at station 801, Fig. 2e).

\section{Step-by-step approach for fault modeling}

To decompose the complex rupture process of the 2012 doublet earthquake, we apply a step-by-step procedure to tsunami, teleseismic, and aftershock data. We first estimate an initial sea-surface height distribution of the tsunami (hereafter, the tsunami source model) by inverting tsunami records. Since seafloor crustal deformations, or tsunamis, are very sensitive to shallow earthquakes, we then estimate the fault model of shallow subevent 2 based on the tsunami source model. We also use aftershocks detected around subevent 2 (Obana et al. 2015) to obtain information on the fault geometry. We then calculate the change in residual sea-surface height between the tsunami source model and the vertical displacement from subevent 2. Given that this residual distribution is caused by subevent 1 , we then estimate the fault model of subevent 1 . Furthermore, because there are large trade-offs between fault size and the focal depth and the amount of slip in a deeper earthquake, we also use the results of teleseismic analyses (Lay et al. 2013; Harada et al. 2013) to obtain prior information on the fault parameters such as fault depth and size for subevent 1.

\section{Tsunami source modeling using near-field tsunami records}

We estimate the tsunami source model by inverting tsunami records via the conventional inversion analysis method (e.g., 
Table 1 List of tsunami stations used in this study

\begin{tabular}{|c|c|c|c|c|c|c|c|}
\hline Station & Latitude $\left[{ }^{\circ} \mathrm{N}\right]$ & Longitude $\left[^{\circ} \mathrm{E}\right]$ & Depth [m] & Epicentral distance [km] & Inversion time window [s] & Instrument & $\begin{array}{l}\text { Sampling rate of } \\
\text { original data }[s]^{\text {a }}\end{array}$ \\
\hline GFK & 37.5812 & 142.7647 & 2245 & 140 & $0-200$ & TPG & 1 \\
\hline P01 & 38.3331 & 142.4167 & 1038 & 180 & $300-1500$ & TPG & 1 \\
\hline P02 & 38.5006 & 142.5035 & 1109 & 180 & $300-1500$ & TPG & 1 \\
\hline P03 & 38.1834 & 142.3996 & 1056 & 170 & $300-1500$ & TPG & 1 \\
\hline P04 & 38.3163 & 142.5657 & 1265 & 160 & $300-1500$ & TPG & 1 \\
\hline P05 & 38.3000 & 142.7004 & 1412 & 150 & $300-1500$ & TPG & 1 \\
\hline P06 & 38.6338 & 142.5833 & 1269 & 180 & $300-1500$ & TPG & 1 \\
\hline P07 & 38.0000 & 142.4486 & 1064 & 170 & $300-1500$ & TPG & 1 \\
\hline P08 & 38.2833 & 142.8329 & 1424 & 140 & $150-1350$ & TPG & 1 \\
\hline P10 & 38.2500 & 143.1666 & 2066 & 110 & $0-1200$ & TPG & 1 \\
\hline P12 & 37.8206 & 142.8996 & 1635 & 130 & $0-1200$ & TPG & 1 \\
\hline KAMN & 38.8862 & 143.3639 & 2360 & 150 & $0-1200$ & TPG & 1 \\
\hline KAMS & 38.6347 & 143.2621 & 2246 & 130 & $0-1200$ & TPG & 1 \\
\hline MYGI & 38.0832 & 142.9166 & 1697 & 130 & $0-1200$ & TPG & 1 \\
\hline G09 & 38.4782 & 143.7922 & 5500 & 90 & Not used & TPG & 1 \\
\hline GJT3 & 38.2948 & 143.4811 & 3260 & 90 & Not used & TPG & 1 \\
\hline JFAST & 37.9336 & 143.9154 & 6799 & 40 & Not used & TPG & 1 \\
\hline TJT1 & 38.2080 & 143.7904 & 5744 & 60 & Not used & TPG & 1 \\
\hline 801 & 38.2325 & 141.6836 & 144 & 240 & Not used & GPS Buoy & 1 \\
\hline 802 & 39.2586 & 142.0969 & 204 & 250 & Not used & GPS Buoy & 1 \\
\hline 803 & 38.8578 & 141.8944 & 160 & 240 & Not used & GPS Buoy & 1 \\
\hline 804 & 39.6272 & 142.1867 & 200 & 320 & Not used & GPS Buoy & 1 \\
\hline 805 & 40.6333 & 141.7500 & 87 & 380 & Not used & GPS Buoy & 1 \\
\hline 806 & 36.9714 & 141.1856 & 137 & 250 & Not used & GPS Buoy & 1 \\
\hline 807 & 40.1167 & 142.0667 & 125 & 320 & Not used & GPS Buoy & 1 \\
\hline KPG1 & 41.7040 & 144.4375 & 2218 & 450 & $1200-2400$ & KPG & 1 \\
\hline KPG2 & 42.2365 & 144.8454 & 2210 & 510 & $1500-2700$ & KPG & 1 \\
\hline KCTD & 41.6675 & 144.3409 & 2540 & 440 & $1200-2400$ & KPG & 10 \\
\hline$J P 1$ & 40.3777 & 146.1681 & 5125 & 330 & $1050-2250$ & DART & 15 \\
\hline$J P 2$ & 39.2849 & 145.7845 & 5183 & 210 & $750-1950$ & DART & 15 \\
\hline
\end{tabular}

${ }^{\mathrm{a}}$ Observed records were resampled to $15 \mathrm{~s}$ in the inversion for the tsunami source model

Tsushima et al. 2012; Inazu and Saito 2014; Kubota et al. 2018a). The details of the procedure are identical to those described in Kubota et al. (2018a). Before estimating the tsunami source model, however, we conduct a preparatory tsunami simulation using the tsunami source model in Inazu and Saito (2014) (Additional file 1: Figure S1). Although the pressure fluctuation at the TPGs was explained roughly, the pressure offset changes at the stations closest to the source (G09, TJT1, JFAST, and GJT3) were not explained at all (Additional file 1: Figure S1). This indicates that the latter is not due to coseismic seafloor deformations. Thus, they are probably due to tilts or rotations in the sensors related to the seafloor strong ground motion (e.g., Wallace et al. 2016; Kubota et al. 2018a).
In calculating the Green's functions for the tsunami, the unit source elements of the seafloor displacements (Kubota et al. 2015, 2018a) are distributed around the focal area. The horizontal dimension of the unit source elements is $20 \mathrm{~km} \times 20 \mathrm{~km}$ at a spacing of $10 \mathrm{~km}$ (overlapping with the adjacent elements), distributed along $260 \mathrm{~km}$ (in the EW direction) $\times 240 \mathrm{~km}$ (NS) area. To calculate the sea-surface displacement from the unit source elements of the seafloor displacement, we consider the spatial filtering effect due to water depth (Saito 2019). In the depth filtering process, we assume a seawater depth of $6 \mathrm{~km}$. To simulate the tsunami, we solve the linear dispersive wave equation in the local Cartesian coordinates (e.g., Saito 2019). The grid spacing is $2 \mathrm{~km}$ 


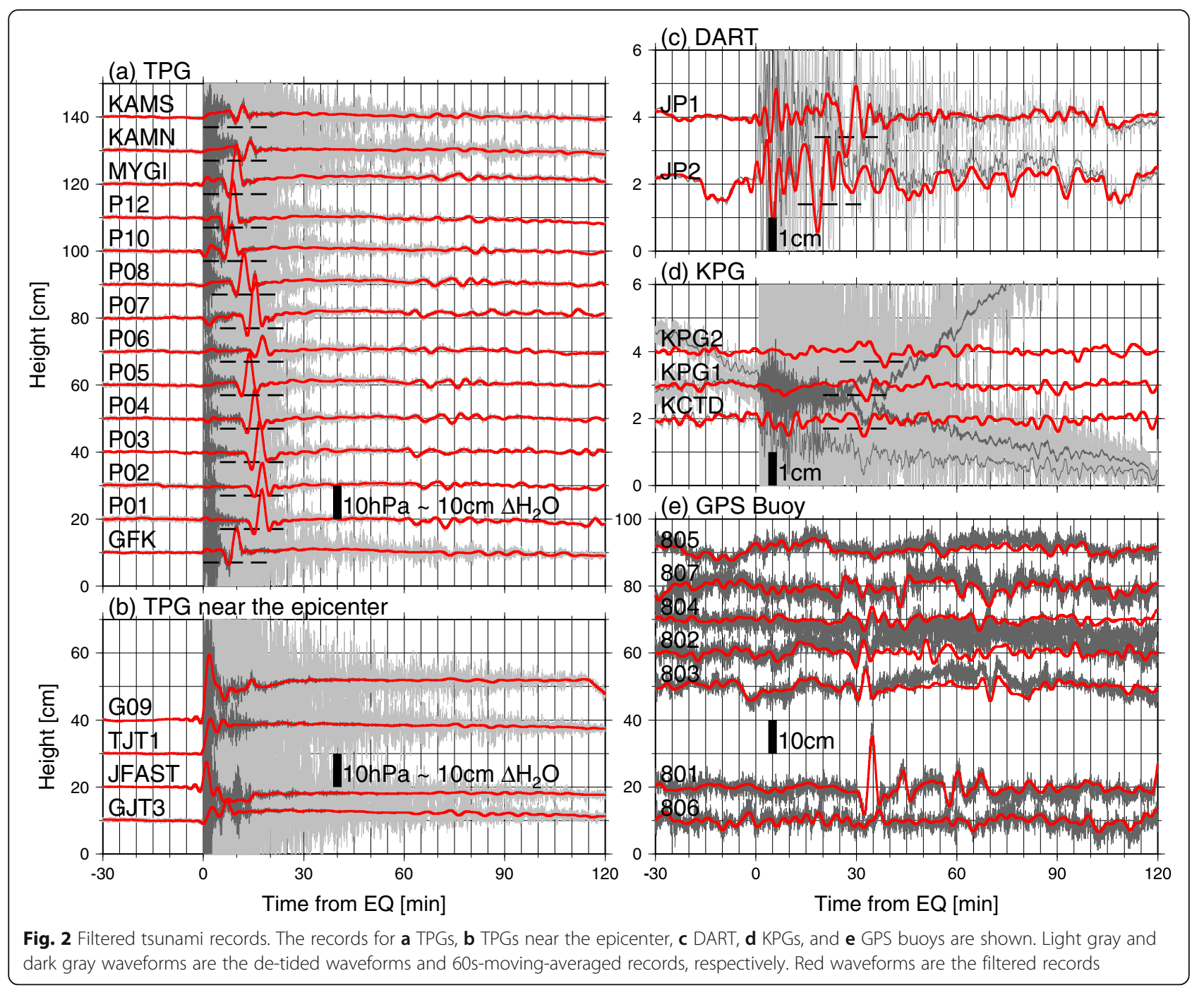

with a $1 \mathrm{~s}$ time step according to interpolation done via ETOPO1 bathymetry data (Amante and Eakins 2009). We assume that the displacements of all unit sources occurred instantaneously and simultaneously. The tsunami propagation velocity expected by the linear long-wave theory is expressed as $v=\left(g_{0} H\right)^{1 / 2}\left(g_{0}\right.$ : gravity acceleration constant, $H_{0}$ : water depth). Given the assumed water depth of $6 \mathrm{~km}$ and the average depth of the focal area, the propagation velocity is approximated as $\sim 240$ $\mathrm{m} / \mathrm{s}(\sim 15 \mathrm{~km} / \mathrm{min})$. Thus, the tsunami propagation distance during the duration of the $\mathrm{M} \sim 7$ earthquake $(\sim 10$ s) and the time interval between two subevents $(\sim 10 \mathrm{~s})$ is about $3 \mathrm{~km}$, which is sufficiently small compared to the extent of the tsunami source model $(\sim 100 \mathrm{~km}$, Inazu and Saito (2014)). We consider the static pressure offsets related to the calculation of Green's function of the PGs for permanent seafloor deformation (Tsushima et al. 2012; Kubota et al. (2018a)). The same filter used for the observed records is applied to the simulated waveforms.
All data is resampled to $15 \mathrm{~s}$ intervals for the inversion. We use different time windows for each station, including tsunami main phase (Table 1, thick black lines in Fig. 3). The smoothing constraint is imposed and its weight is determined based on the trade-off between the weight and reduction in variance between the observed and simulated tsunami waveforms (Additional file 1: Figure S2). Since the G09, TJT1, JFAST, and GJT3 stations are located near the source and are probably affected by seafloor ground shaking (Additional file 1: Figure S1), we exclude these records from the inversion analysis. Since all TPG stations are located landward of the source region, the constraint for the eastern edge of the tsunami source is likely not very good. Therefore, to improve the source constraint further, we also use the DART and KPG records. Since the amplitudes of TPG records are approximately ten times larger than the DART and KPG records, we weight the KPG and DART data at values ten times that of the TPG data. 


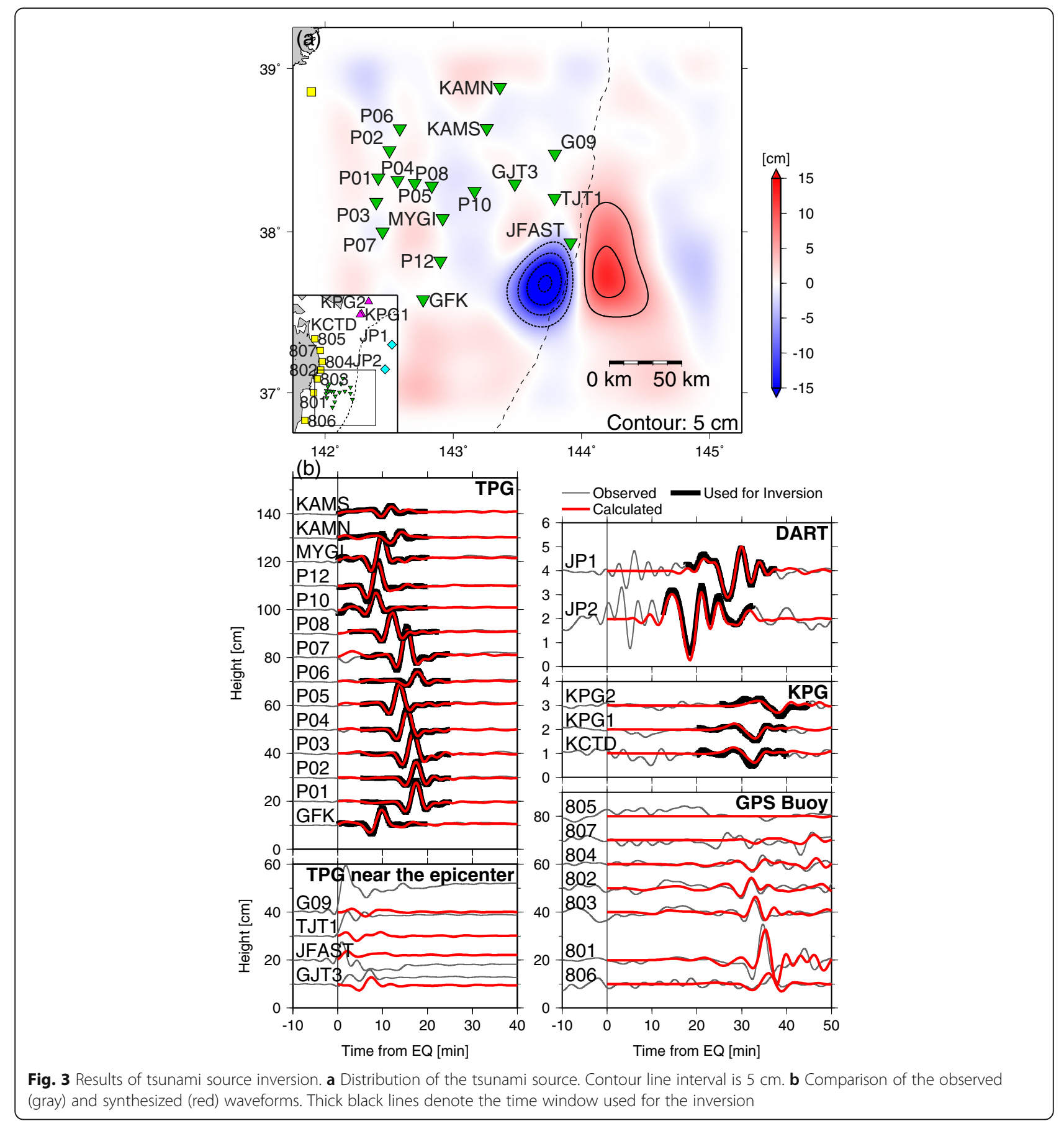

Fault modeling of subevent 2

Because we found that the subsidence of the tsunami source was generated by the shallow subevent 2 (see Fig. 4 and Tsunami source model subsection in Results and Discussion section), we first estimate a fault model for subevent 2, which best explains the subsidence region of the tsunami source model. We use the grid-search approach proposed by Kubota et al. (2015, 2018b), which estimates an optimum rectangular planar fault model with uniform slip. Because the short-wavelength component disappeared in the tsunami source model due to the smoothing constraint imposed in the inversion and the spatial smoothing effect used in the deep-sea region during the tsunami generation (see Fig. 4 and Tsunami source model subsection in Results and Discussion section), we consider the smoothing effect in fault modeling by the following procedure. First, we calculate the seafloor deformation using a fault model candidate (a set of unknown parameters) (Okada 1992) and then simulate a tsunami. The simulated waveforms are inverted to 

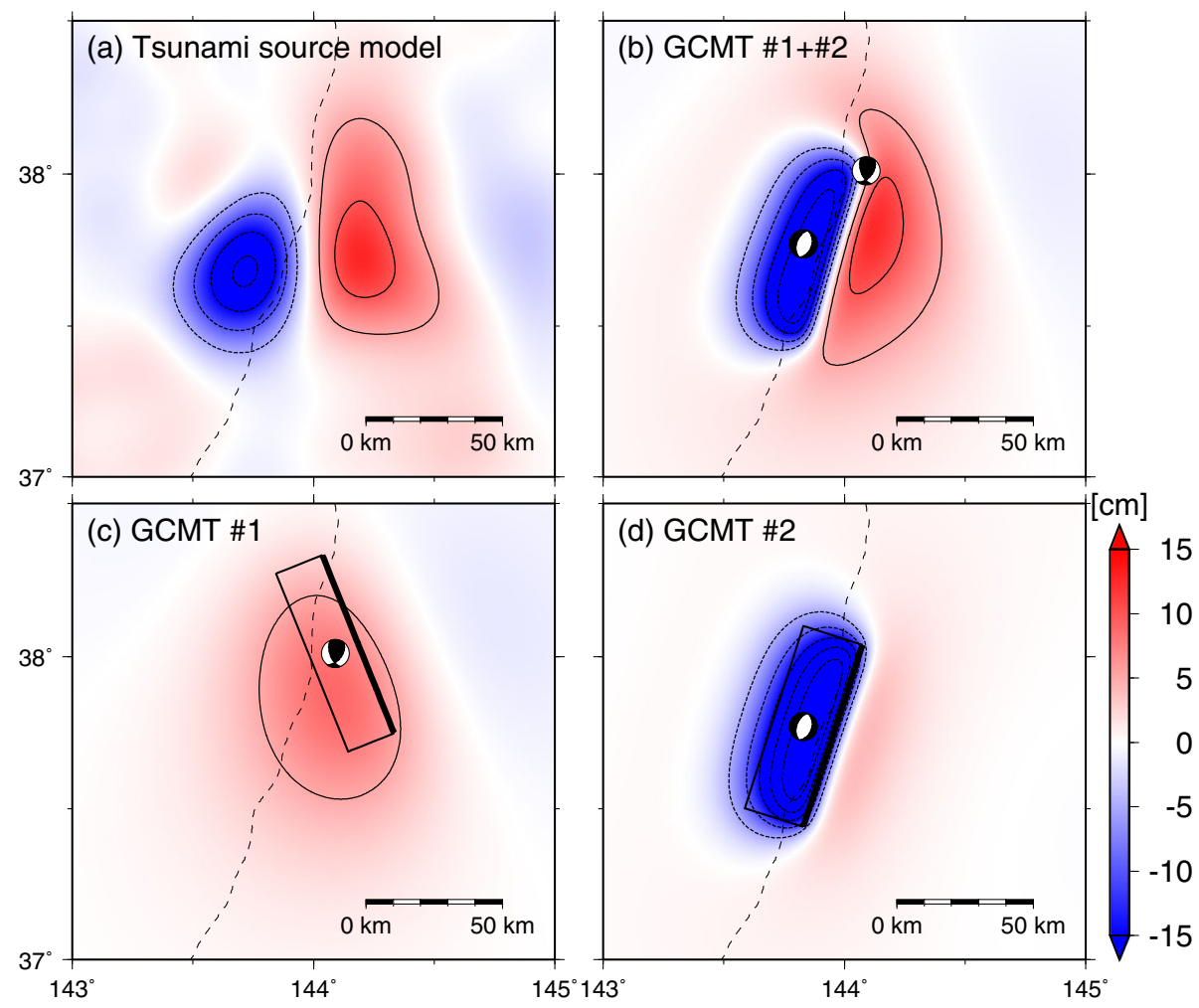

Fig. 4 Sea-surface displacement expected from the GCMT solution. Displacements from $\mathbf{a}$ the tsunami source model, $\mathbf{b}$ the combination of both subevents, $\mathbf{c}$ subevent 1 , and $\mathbf{d}$ subevent 2 . The faults are represented by black rectangles

obtain the initial sea-surface height distribution, under the same conditions used in the inversion for the tsunami source model. Finally, we evaluate the goodness of the tsunami waveform fitting from the fault model candidate, by comparing the subsided area of the tsunami source model and the inverted sea-surface height.

The geometry of the fault plane is assumed to be on the west-dipping plane of GCMT solution (strike $=189^{\circ}$ and dip $=50^{\circ}$ ), which is consistent with the planar structure of the aftershock (Obana et al. 2015). We also assume the rake angle from the GCMT solution $\left(=-90^{\circ}\right)$. Because the aftershock alignment is located $\sim 2 \mathrm{~km}$ west from the GCMT centroid, the fault plane is constrained to pass through the point that is $2 \mathrm{~km}$ west from the GCMT centroid (hereafter, referred to as the reference point). The unknown parameters are the distance from the reference point to both ends of the fault, along the strike (i.e., length) and dip (width) direction $\left(L_{1}, L_{2}, W_{1}\right.$, and $W_{2}$; see Fig. $5 \mathrm{c}$ and d). The search range for these parameters is determined based on the aftershocks and the horizontal extent of the subsidence area of the tsunami source. The fault length $\left(L=L_{1}+L_{2}\right)$ is assumed to be greater than the fault width $\left(W=W_{1}+W_{2}\right)$, as $L$ $>W$. The top of the fault plane (defined by parameter $W_{2}$ ) is constrained as not to extend above the seafloor.
The fault model candidate is assessed through variance reduction (VR) of the subsided areas between the tsunami source model and the fault model candidate:

$$
\begin{aligned}
\mathrm{VR}= & \left(1-\frac{\sum_{i=1}^{N}\left(x_{i}^{\text {source }}-D x_{i}^{\text {candidate }}\right)^{2}}{\sum_{k=1}^{N}\left(x_{i}^{\text {source }}\right)^{2}}\right) \\
& \times 100(\%),
\end{aligned}
$$

where $x_{i}^{\text {source }}$ and $x_{i}^{\text {candidate }}$ are the displacements of the sea-surface at the $i$ th grid point, from the tsunami source model and the fault model candidate assuming the unit slip, respectively. $N$ is the total number of grid points. The slip amount on fault $D$ is determined so that the VR takes the maximal value. We use the grid points within the subsided area of the tsunami source model (blue dashed line in Fig. 5a) to calculate the VR. The search range of the unknown parameters is listed in Table 2.

\section{Fault modeling of subevent 1}

In order to estimate the fault model of subevent 1 , we use the residual sea-surface height between the tsunami source model and the sea-surface displacement expected from the fault model of subevent 2 (hereafter, referred 

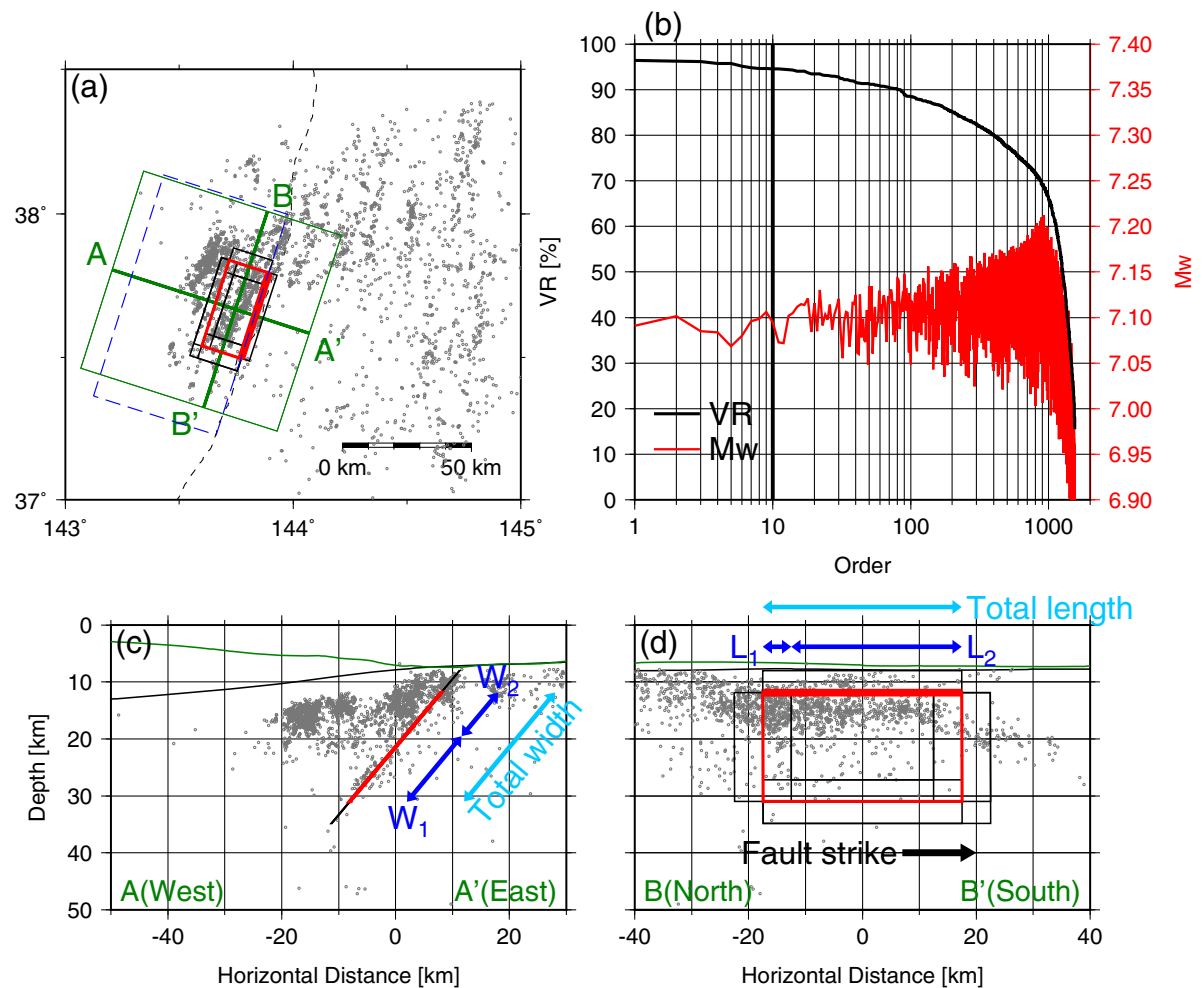

Fig. 5 Results for the grid-search of subevent 2. a The optimum fault model is shown by the red rectangle. The top ten fault model candidates are shown by thin black rectangles. $\mathbf{b}$ VR (black) and Mw (red) of the fault model candidates searched in the grid-search, arranged in the descending order in terms of VR. The rectangle with blue dashed lines denotes the area used for calculating VR. c, $\mathbf{d}$ Vertical profile along A-A' and $\mathbf{B}-B^{\prime}$ lines in $\mathbf{a}$. Aftershocks are taken from the rectangular area with the green lines in $\mathbf{a}$. The configuration of the fault parameters is also shown

Table 2 Search range of the grid-search for fault modeling

\begin{tabular}{|c|c|c|}
\hline & Subevent 2 & Subevent 1 \\
\hline Reference point latitude [ $\left.{ }^{\circ} \mathrm{N}\right]$ & $37.77^{c}$ & $37.6-38.1^{d}$ \\
\hline Reference point longitude $\left[^{\circ} \mathrm{E}\right]$ & $143.81^{c}$ & $143.8-144.5^{d}$ \\
\hline Reference point depth $[\mathrm{km}]^{\mathrm{a}}$ & 19.5 & 57.8 \\
\hline Strike $\left[{ }^{\circ}\right]^{a}$ & 189 & 158 \\
\hline $\operatorname{Dip}\left[^{\circ}\right]^{\mathrm{a}}$ & 50 & 59 \\
\hline Rake $\left[{ }^{\circ}\right]^{a}$ & -90 & 48 \\
\hline$L_{1}[\mathrm{~km}]^{\mathrm{b}}$ & $0,5,10, \ldots, 50^{e}$ & 15 \\
\hline$L_{2}[\mathrm{~km}]^{\mathrm{b}}$ & $0,5,10, \ldots, 50^{e}$ & 15 \\
\hline$W_{1}[\mathrm{~km}]^{\mathrm{b}}$ & $10,15,20, \ldots, 40^{e}$ & 10 \\
\hline$W_{2}[\mathrm{~km}]^{\mathrm{b}}$ & $10,15^{\mathrm{e}}$ & 10 \\
\hline Slip amount $[\mathrm{m}]^{\mathrm{b}}$ & Adjusted so that $\mathrm{t}$ & \\
\hline
\end{tabular}

${ }^{\mathrm{a} S t r i k e, ~ d i p, ~ r a k e ~ a n g l e s, ~ a n d ~ r e f e r e n c e ~ p o i n t ~ d e p t h ~ w e r e ~ f i x e d ~ t o ~ t h e ~ G C M T ~ v a l u e ~}$

${ }^{\mathrm{b}}$ Rectangular fault model with uniform slip is assumed. The fault length $\left(L=L_{1}+L_{2}\right)$ was assumed to be greater than the fault width $\left(W=W_{1}+W_{2}\right)$

${ }^{\mathrm{C}} \mathrm{A}$ point $2 \mathrm{~km}$ west of the GCMT centroid

dHorizontal location of reference point was searched within the range of $\pm 30 \mathrm{~km}$ in the EW and NS direction from the centroid location of Lay et al. (2013)

$\left(37.82^{\circ} \mathrm{N}, 144.13^{\circ} \mathrm{E}\right)$, with increments of $5 \mathrm{~km}$

${ }^{\mathrm{e}}$ Increments for the fault length and width are $5 \mathrm{~km}$ 
to as the residual height distribution). This is because the residual height distribution is expected to correspond to the sea-surface displacement due to subevent 1 . Because subevent 1 occurred at the deeper part of the incoming plate, it appears to be difficult to constrain the fault parameters such as fault geometry, depth, size, and slip amount only from the residual height distribution. Meanwhile, the residual height will contribute to constrain the horizontal location of the fault. Thus, we use the results of the teleseismic analyses in previous studies (GCMT; Lay et al. 2013; Harada et al. 2013) to obtain prior information on the fault parameters. We fix the centroid depth, fault geometry (strike, dip, and rake angles), and fault dimension (length and width) based on previous teleseismic analyses. We estimate the optimum horizontal location (longitude and latitude) of the fault and the amount of uniform slip on the rectangular fault using the grid-search approach, as in the fault modeling of subevent 2 .

Because Lay et al. (2013) investigated the CMT solution of the 2012 doublet earthquake using the teleseismic W-phase waveforms and showed and discussed the uncertainty of their estimations in detail, we use the CMT solution proposed by them as prior information for our fault modeling. We assume the centroid depth as $60.5 \mathrm{~km}$ and the west-dipping nodal plane with geometry of strike $=163^{\circ}$ dip $=51^{\circ}$, and rake $=57^{\circ}$. The slip distribution of subevent 1 obtained by the teleseismic analysis (Lay et al. 2013; Harada et al. 2013) had a main rupture area with a dimension of $L \sim 30 \mathrm{~km}$ and $W \sim 20$ $\mathrm{km}$; therefore, we fix the fault length and width as 30 and $20 \mathrm{~km}$, respectively $\left(L_{1}=L_{2}=15 \mathrm{~km}\right.$ and $W_{1}=W_{2}$ $=10 \mathrm{~km}$ ). The search range of the horizontal location of the centroid is determined based on the evaluation of the uncertainty of the horizontal location of the Wphase analysis of Lay et al. (2013) (see Figure S2 in Lay et al. 2013). The search range is listed in Table 2.

\section{Results and Discussion}

\section{Tsunami source model}

We obtained a tsunami source distribution that had a pair of large uplifts and subsidences (Fig. 3a). The observed waveforms (red lines in Fig. $3 \mathrm{~b}$ ) were reproduced well. The GPS buoy waveforms, which were not used for the inversion, were also explained. Furthermore, although the offset changes at the stations near the source (G09, TJT1, JFAST, and GJT3) were not reproduced, the fluctuations in the calculated waveforms were similar to the observations. This is consistent with the idea that these changes were due to the tilting or rotation of the sensors (e.g., Wallace et al. 2016; Kubota et al. 2018a).

To investigate the contribution from each subevent on the tsunami source, we compute the sea-surface vertical displacement from the GCMT solution and compared the results with the tsunami source model. We use the equation in Okada (1992), which assumes that the rectangular planar fault on the west-dipping nodal plane has a uniform slip. For simplicity, values of length, width, and slip $L=70 \mathrm{~km}, W=35 \mathrm{~km}$, and $D=0.7 \mathrm{~m}$, respectively, are used. The spatial pattern of the tsunami source model (Fig. 4a) is similar to that of the combined deformation of subevents 1 and 2 (Fig. 4b) and the subsidence area is similar to that expected from the CMT solution of subevent 2 (Fig. 4d). The uplift of the tsunami source model is not consistent with either subevent 1 nor 2 alone (Fig. 4c and d). Based on this comparison, we conclude that the subsidence is generated by subevent 2 alone and that both subevents contribute to the uplift. The deformation expected from subevent 2 (Fig. 4d) has a sharp displacement peak that was not estimated in the tsunami source model. This is probably because the short-wavelength components disappeared due to the smoothing constraint imposed in the inversion and the spatial smoothing effect used in the deep-sea region during the tsunami generation (Saito 2019).

\section{Fault models of two subevents of the 2012 doublet earthquake}

We obtained an optimum fault model of subevent 2, which had the highest VR value among all the fault model candidates, with a length of $35 \mathrm{~km}\left(L_{1}=5 \mathrm{~km}, L_{2}\right.$ $=30 \mathrm{~km})$, width of $25 \mathrm{~km}\left(W_{1}=15 \mathrm{~km}, W_{2}=10 \mathrm{~km}\right)$, and fault slip of $1.1 \mathrm{~m}(\mathrm{VR}=96 \%$, Fig. 5). The seismic moment was $5.5 \times 10^{19} \mathrm{Nm}$ (Mw 7.1, assuming the rigidity of $60 \mathrm{GPa}$ ). The VR values for all fault model candidates (in the descending order) are shown in Fig. 5b. The VR values for the top ten candidates are almost flat and relatively high (Fig. 5d). This indicates that the top ten candidates reasonably reconstruct the subsidence of the tsunami source model. Hence, we inspect the model parameters for these candidates to evaluate the estimation error of the optimum fault model. They are projected onto the vertical cross-section in Fig. $5 \mathrm{c}$ and $\mathrm{d}$ (thin black lines), and the histograms of the model parameters are shown in Fig. 6. Among the top ten candidates, most models have the down-dip limit of the fault plane of $W_{1}=15 \mathrm{~km}$, and all models have fault bottoms shallower than the depth of $\sim 35 \mathrm{~km}\left(W_{1} \leq 20 \mathrm{~km}\right.$, Fig. 6). This indicates that the lower end of the fault of subevent 2 should be less than $\sim 35 \mathrm{~km}$.

We also calculated the sea-surface height assuming the faults with smaller dimension with larger slip (Additional file 1: Figure S3). In this calculation, the down-dip end of the fault $\left(W_{1}\right)$ and slip amount were changed, and the length $\left(L_{1}, L_{2}\right)$ and the up-dip end $\left(W_{2}\right)$ of the fault, and seismic moment Mo were fixed to those of the optimum model. In the fault models 


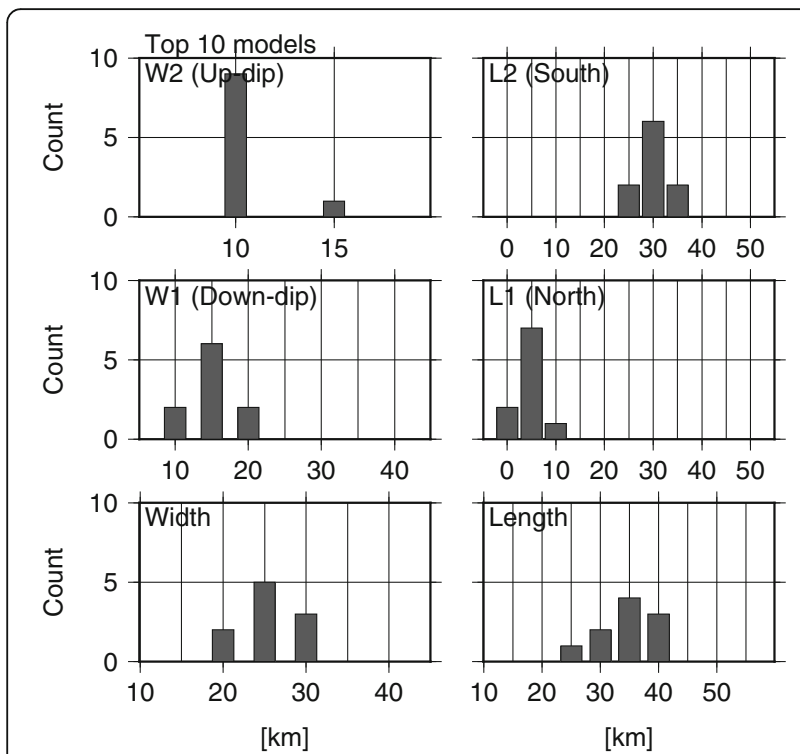

Fig. 6 Histograms of the top ten model parameters in the gridsearch of subevent 2 with $W<15 \mathrm{~km}$ (down-dip depth of fault is shallower than $\sim 25 \mathrm{~km}$ ), the locations of the western edge of the subsided area and of the peak displacement are inconsistent with those of the tsunami source model. This indicates the small fault models are implausible. The subsidence of the tsunami source model could be explained when the small faults are located slightly west of the optimum fault location. However, such faults can be rejected because we used the aftershock distribution of Obana et al. $(2014,2015)$ to constrain the horizontal location of the fault. It is important to use the aftershock distribution for prior information on the fault horizontal location, in order to accurately constrain the down-dip depth of the subevent 2 fault.

The subsided area calculated from the optimum fault model was consistent with that of the tsunami source model (Fig. 7a and b). We calculate the residual sea-surface height between the tsunami source model (Fig. 7a) and the sea-surface displacement expected from the fault model of subevent 2 (Fig. $7 \mathrm{~b}$; the residual height distribution).

From the residual height distribution utilizing the results of the teleseismic analyses, we constrained the fault
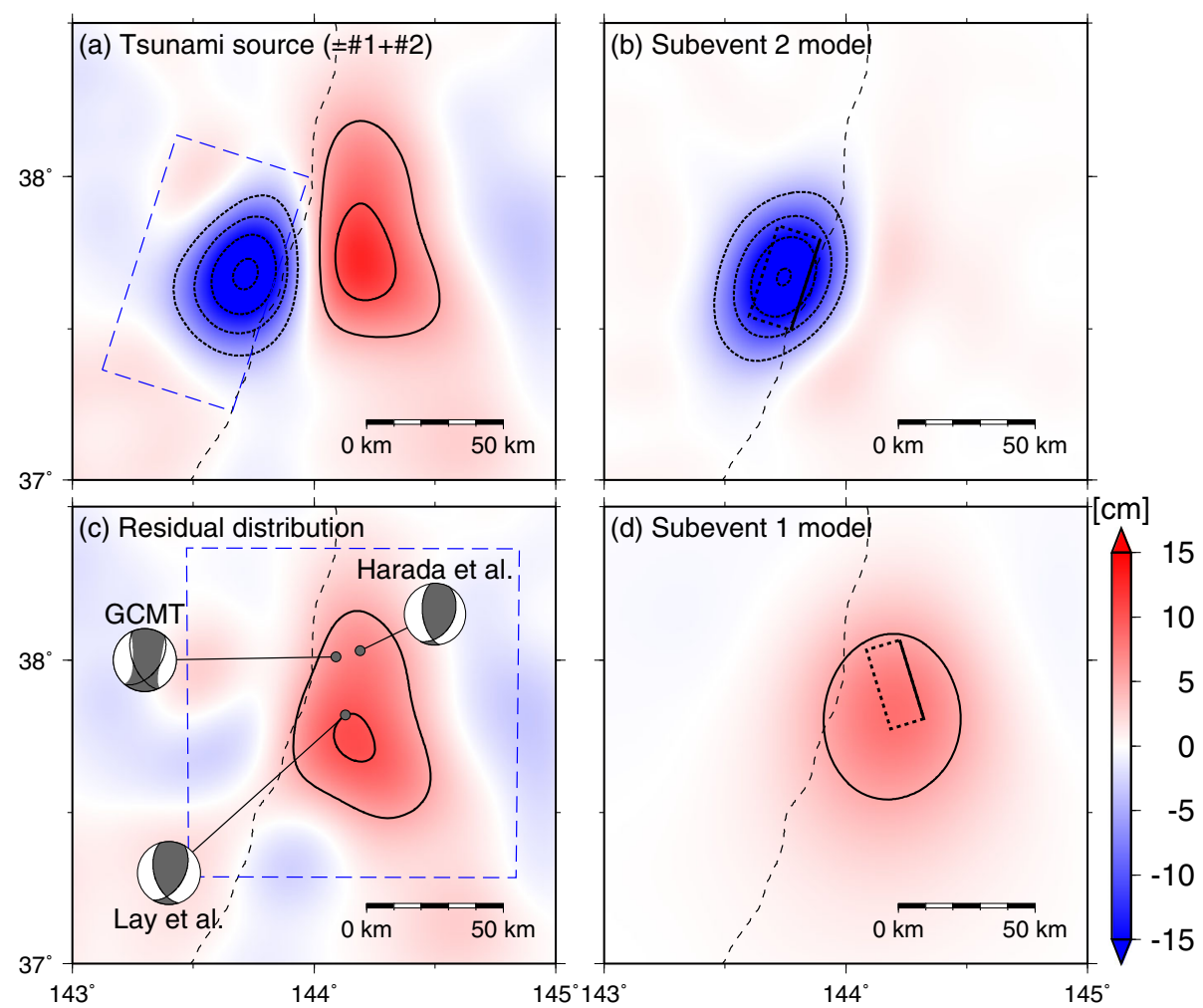

Fig. 7 Sea-surface height changes from the models in the present study. a The tsunami source model with contour intervals of $5 \mathrm{~cm}$. The rectangular area enclosed by the blue dashed lines denotes the area used for the fault modeling of subevent 2. b Subevent 2 fault model; the optimum fault is also shown. $\mathbf{c}$ the residual between $\mathbf{a}$ and $\mathbf{b}$. CMT solutions for subevent 1 by GCMT, Lay et al. (2013) and Harada et al. (2013) are also shown. The rectangular area enclosed by the blue dashed lines is the area used for the fault modeling of subevent 1 . $\mathbf{d}$ the subevent 1 fault model; the optimum fault is also shown 
model of subevent 1. The result is shown in Fig. 8. The slip amount on the fault was $2.2 \mathrm{~m}$, and the seismic moment was $7.8 \times 10^{19} \mathrm{Nm}(\mathrm{Mw} 7.2$, rigidity of $60 \mathrm{GPa})$. We obtained the optimum VR of $80 \%$. The VR values are relatively high and flat for the top ten fault model candidates (Fig. 8b). The uncertainty of the horizontal location of the fault center for these candidates is likely to be $\pm \sim 10 \mathrm{~km}$ (Fig. 8a). This horizontal uncertainty is almost consistent with that estimated by Lay et al. (2013).

\section{Tsunami and teleseismic waveform simulation from optimum fault model}

The results of the fault modeling of the 2012 doublet earthquake are summarized in Fig. 9. The sea-surface height displacement expected from the optimum rectangular fault models of subevents 1 and 2 (Fig. 9a) is calculated by the superposition of the displacements from each fault model (Figs. 5a and 8a). The distribution is very similar to that of the tsunami source model (Fig. 4). The optimum models have vertical ranges of $\sim 6$ (seafloor)- $30 \mathrm{~km}$ for shallow subevent 2 and $\sim 50-70 \mathrm{~km}$ for deep subevent 1 (Fig. 9d and e).

From the combined displacement, we numerically simulate tsunami waveforms (Fig. 10). The simulated waveforms reasonably explained the observed tsunami waveforms well, not only the near-field TPGs but also the far-field DART, KPG, and GPS buoys (red lines in Fig. 10b). We calculate the VR between the observed and calculated waveforms from Eq. (1), by using the same time window as in the inversion of tsunami records. We finally obtained VR $=79 \%$.
We also simulate the teleseismic $\mathrm{P}$-waves using the fault model parameters for comparison with the observed teleseismic waveforms (Fig. 11). We assume pure doublecouple point sources at the centers of the optimum faults of each subevent. We use the calculation programs of Kikuchi and Kanamori (2003). A triangular-shaped source time function with the rise time of $6 \mathrm{~s}$ is assumed, considering the typical rupture duration of $M \sim 7$ earthquakes (Fig. 9b). After simulating the waveforms of each subevent, we stack the simulated waveforms. We assume that the difference of focal times between subevents 1 and 2 was $10 \mathrm{~s}$, which is determined by inspecting the waveform similarity of the observed and stacked waveforms.

We use a 1D multi-layered velocity structure model without the water layer, assuming that the source structure was identical to the receiver structure in Table 3 (blue traces in Fig. 11b). The simulated waveforms for each subevent are also shown in Additional file 1:Figure S4. The peak timing and amplitudes of the first up-motion and the subsequent down-motion waves reasonably fitted the observation, although the subsequent phases during $50-80 \mathrm{~s}$ did not perfectly match. This is probably because of the assumptions of the velocity structure and simple source time function. We then simulate the teleseismic waveforms incorporating the water layer and oceanic structure, shown in Table 3 (red traces in Fig. 11b). The agreement of the subsequent phases improved compared with the simulation without the water layer. According to the teleseismic analysis by Lay et al. (2013), another smaller normal-faulting subevent was estimated at $40 \mathrm{~s}$

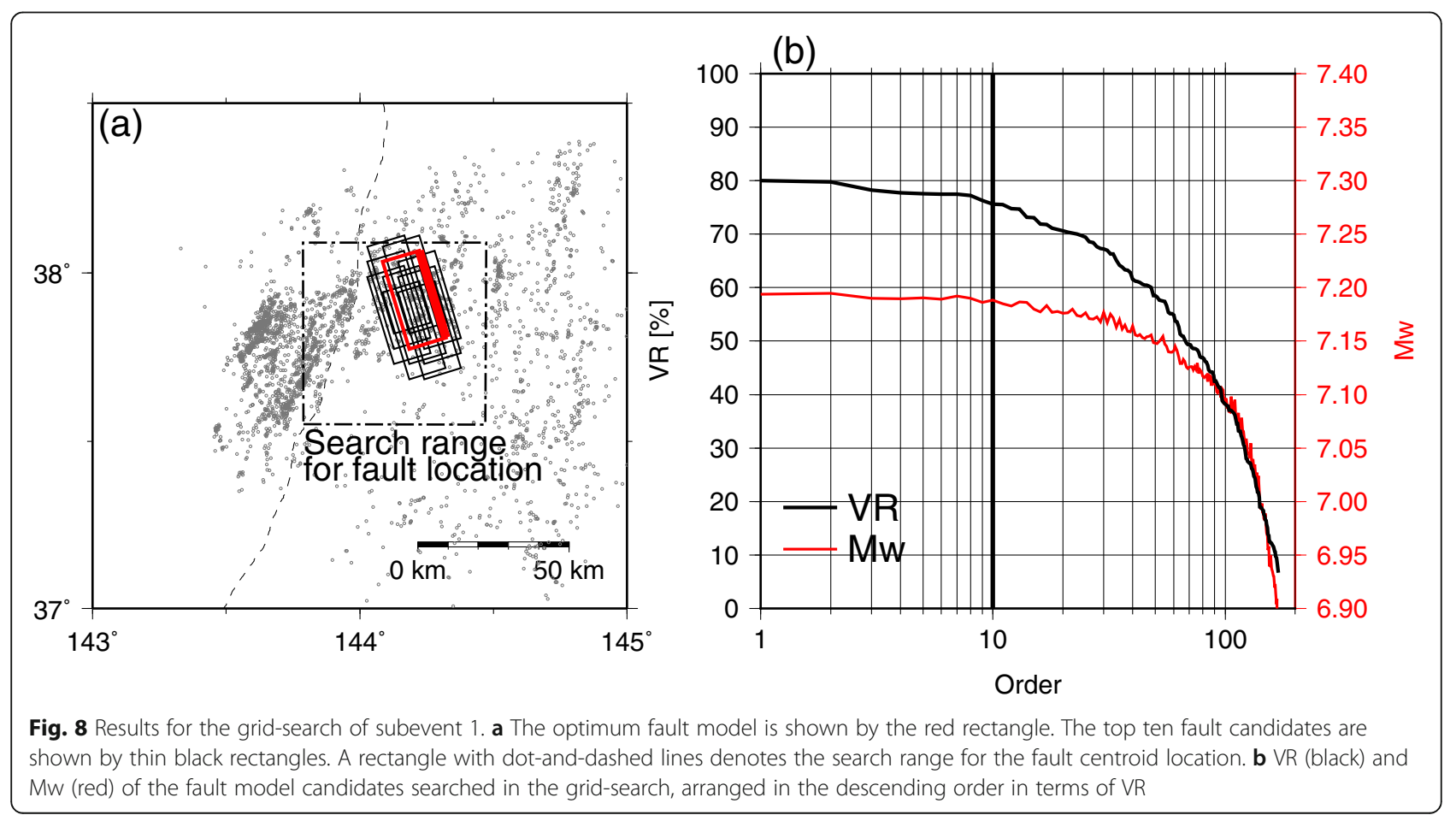



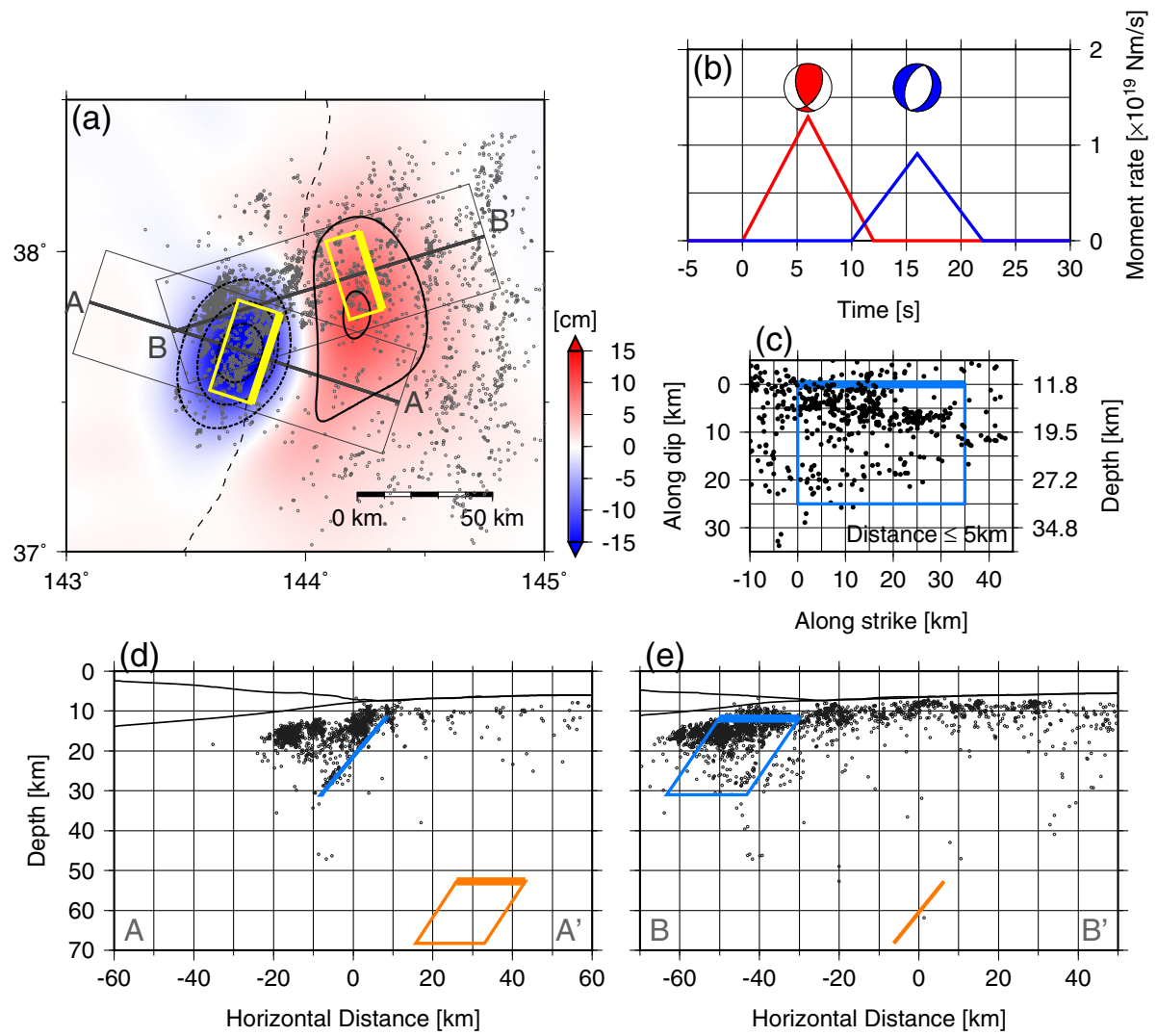

Fig. 9 Summary of the fault modeling. a Sea-surface height distribution calculated from the superposition of the those from the fault models of subevents 1 and 2. Locations of the optimum faults are also shown. $\mathbf{b}$ The moment rate function used for the teleseismic waveform calculation. $\mathbf{c}$ Aftershock distribution on the fault plane of subevent 2. Aftershocks with distances from the fault plane smaller than $5 \mathrm{~km}$ are shown. $\mathbf{d}$, e Vertical profile along A-A' and B-B' lines in $\mathbf{a}$. Orange and blue rectangles are the optimum fault models of subevents 1 and 2, respectively. Aftershocks are taken from the rectangular areas in $\mathbf{a}$

after subevent 1 . Hence, it is possible that the third smaller subevent also contributed to the generation of the later arrival. It is worth pointing out that it is important to use the teleseismic records to resolve the temporal complexity of the doublet earthquake in detail.

Our fault model explains both tsunami and teleseismic observations. In addition, our fault model of subevent 2 is consistent with the aftershock distribution determined by the ocean bottom seismographs. The rupture area of subevent 2 estimated by Harada et al. (2013) was located at the outer-trench region and concentrated in the shallower portion of the plate $(z<\sim 20 \mathrm{~km})$. The horizontal location of subevent 2 centroid by Lay et al. (2013) (Fig. 1b) was also inconsistent with our fault model and with the aftershock locations. The consistency of our fault model with the tsunami, teleseismic waveforms, and aftershocks indicates that the step-by-step procedure used in this analysis can decompose the complex rupture process of the 2012 doublet earthquake. We conclude that we can obtain a more comprehensive fault model of the 2012 doublet earthquake, than the one estimated from the teleseismic data alone.

\section{Importance of near-field tsunami data for the fault modeling}

Inazu and Saito (2014) showed a tsunami source model of the 2012 doublet earthquake using offshore tsunami stations located more than $200 \mathrm{~km}$ from the source area (Additional file 1: Figure S1). We compare the tsunami source models of this study with that of Inazu and Saito (2014) (Fig. 12a). The horizontal location of the tsunami source was in agreement with the model of Inazu and Saito (2014), although the amplitudes were lower. The simulated tsunami at the TPG stations using the tsunami source model of Inazu and Saito (2014) is similar to the tsunami peak timing of the observation (Fig. 12b). This indicates that the horizontal location of the tsunami source is reasonably constrained even when using tsunami stations located far from the source $(>\sim 200 \mathrm{~km})$.

However, the dominant period and amplitudes of the simulated waveforms are longer and smaller than the observation. This indicates that the spatial resolution of the far-field tsunami data is not sufficient for the finite fault model, and thus, to constrain the down-dip limit of the fault plane of subevent 2. Using the near-field 

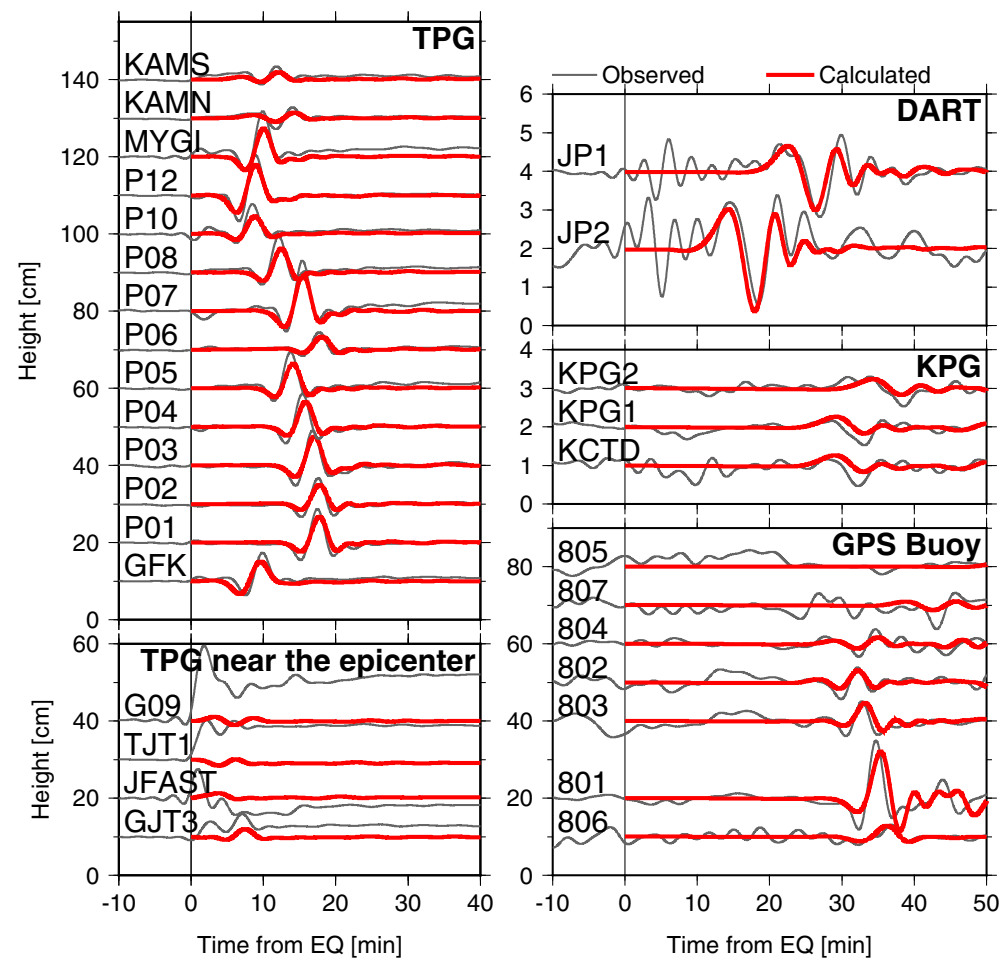

Fig. 10 Comparison of the observed (gray) and calculated (red) waveforms based on the superposition of the optimum fault models of subevents 1 and 2

tsunami data, the constraint of the down-dip limit of the fault plane of shallow subevent 2 is improved. This enables us to discuss the intraplate stress regime after the 2011 Tohoku-Oki earthquake.

The fault dimension and depth of subevent 1 estimated in this study are consistent with previous results of the teleseismic waveforms (Lay et al. 2013; Harada et al. 2013). This is because we used the teleseismic analyses as the prior information for fault dimension. In contrast, the horizontal location and fault dimension of subevent 2 differ from the teleseismic analyses. The down-dip limit of subevent 2 constrained from the teleseismic analysis (Harada et al. 2013) is considerably shallower $(<\sim 20 \mathrm{~km})$ than that of the constrained from tsunami data $(\sim 40 \mathrm{~km})$. Our fault model has better consistency with the aftershock distribution, for both horizontal location and depth range. It is likely that the rupture process of subevent 2 was not resolved well from the teleseismic data, because the teleseismic signal from subevent 2 overlaps with that of subevent 1 . By using the nearfield tsunami records, the resolution of subevent 2 rupture was considerably improved.

\section{Temporal change in down-dip limit of normal-faulting earthquake}

The normal-faulting aftershocks around subevent 2 (Obana et al. 2014, 2015) mainly occurred at depths of $\sim 30 \mathrm{~km}$, which corresponds to the down-dip depth of the optimum fault of subevent 2 (Fig. 9b). Some normalfaulting seismicity also occurred at depths of $\sim 35 \mathrm{~km}$, along the down-dip direction (Fig. 9b). According to Obana et al. (2014), the estimation error of the aftershocks is less than $5 \mathrm{~km}$ (Figure 2 in Obana et al., 2014). Considering the estimation error of the fault model and aftershock distribution, the down-dip limit where the shallow normal-faulting seismicity can occur around this region is $\sim 30-35 \mathrm{~km}$ (Fig. 13).

We also investigate the temporal change of the intraplate seismicity before and after the Tohoku-Oki earthquake (Fig. 13). The down-dip limit of subevent 2 fault $(\sim 35 \mathrm{~km})$ is clearly $\sim 10 \mathrm{~km}$ deeper, compared with the down-dip limit of the normal-faulting seismicity observed in 2007 (< 25 km, Hino et al. 2009). Because both researches use the arrays of the ocean bottom seismometers installed just above the focal area, which have identical sensitivity and were distributed with almost identical spatial intervals $(\sim 10 \mathrm{~km})$, the detectability in both observation periods is expected to be identical and thus the difference between the seismicity depths of the lower limit of the shallow normal-faulting seismicity was confidentially significant. In addition, a few deeper (> $\sim 40 \mathrm{~km}$ ) events were detected in both observations. This also suggests the misdetection of the deeper shallow normal-faulting event $(\sim 30-40 \mathrm{~km})$ before the TohokuOki earthquake is unlikely to occur. 


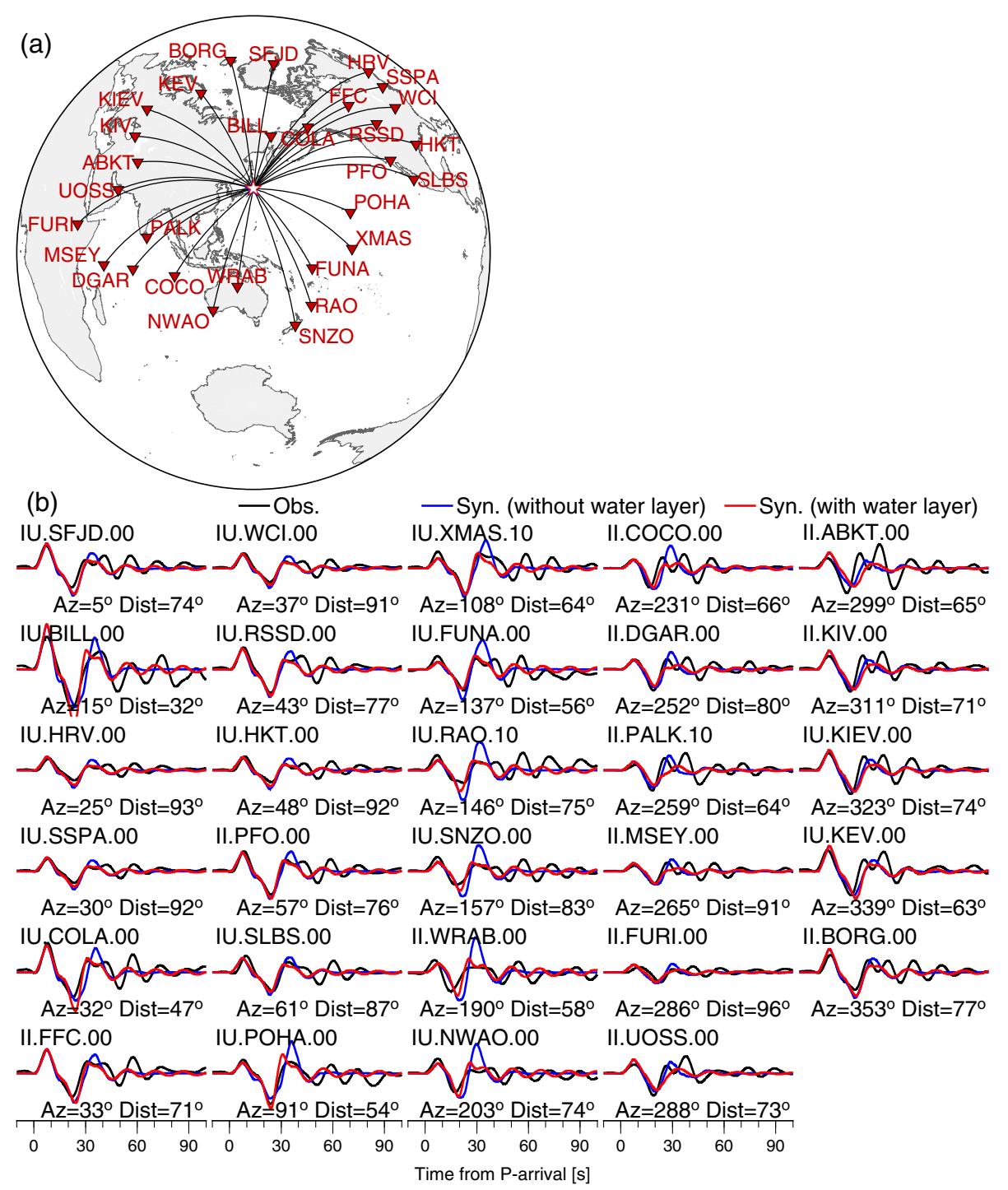

Fig. 11 Results of the forward calculation of the teleseismic waveforms based on the optimum fault model. a Locations of the teleseismic stations. b Comparison of the teleseismic waveforms. Black lines are the observed waveforms, and the synthetic waveforms using the velocity structure with and without the water layer are shown by red and blue lines, respectively. The bandpass filter of 10-500 s is applied

Table 3 Velocity structure used for the teleseismic calculation ${ }^{2}$

\begin{tabular}{llllll}
\hline Structure & \# of layer & $V_{p}[\mathrm{~km} / \mathrm{s}]$ & $V_{p}[\mathrm{~km} / \mathrm{s}]$ & $\rho\left[\mathrm{g} / \mathrm{cm}^{3}\right]$ & $H[\mathrm{~km}]$ \\
\hline Source & 3 & 1.50 & 0.00 & 1.00 & 6.0 \\
& 6.00 & 3.50 & 2.70 & 6.0 \\
\multirow{2}{*}{ Receiver } & 3 & 8.10 & 4.70 & 3.30 & Half space \\
& 6.00 & 3.50 & 2.70 & 18.0 \\
& 6.75 & 3.80 & 2.80 & 18.0 \\
& 8.10 & 4.70 & 3.30 & Half space
\end{tabular}

The structure is based on Kikuchi and Kanamori (1991) but the water layer (thickness of $6 \mathrm{~km}$ ) is assumed for the source structure
In contrast, the up-dip limits of the subevent 1 fault $(\sim 50 \mathrm{~km})$ and the deep reverse-faulting seismicity $(\sim 50$ $\mathrm{km}$, Obana et al. 2015) are almost equivalent to the deep reverse-faulting seismicity before the Tohoku-Oki earthquake (Seno and Gonzalez 1987; Hino et al. 2009), although it is difficult to discuss this in detail because of the very low seismicity. By focusing on the shallow normalfaulting seismicity, we discuss the cause of the deepening of the down-dip limit of the normal-faulting seismicity.

The yield strength of the plate is characterized by the brittle rupture at the shallow portion and ductile failure laws at the deeper parts of the plate (Fig. 14a, e.g., Scholtz 1988; Turcotte and Schubert 2002; Hunter and Watts 2016). Based on the Anderson theory of faulting, the brittle strength along the horizontal direction normal 


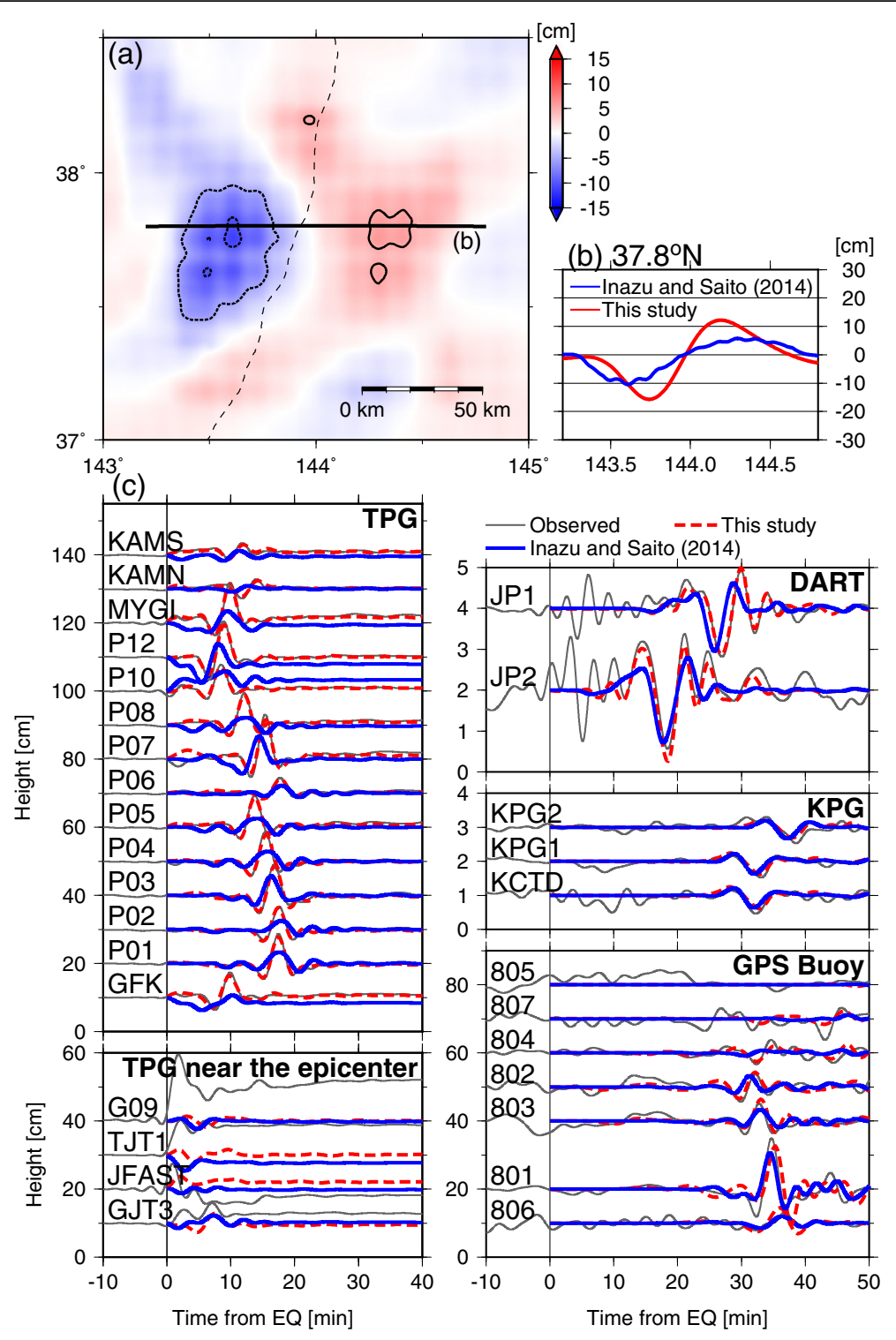

Fig. 12 Comparison with the result of Inazu and Saito (2014). a Tsunami source model of Inazu and Saito (2014). b Cross-section of the tsunami sources from this study (red line) and Inazu and Saito (2014) (blue) at $37.8^{\circ} \mathrm{N}$. c Comparison of the observed waveforms (gray) and synthesized waveforms. Blue dashed and red lines are synthesized using the tsunami source model of the present study and Inazu and Saito (2014), respectively

to the trench axis $\tau_{x x}(z)$ is expressed as (e.g., Turcotte and Schubert 2002):

$$
\tau_{x x}(z)=\frac{2 \mu\left(\rho_{0} g_{0} z-p_{w}\right)}{\sin 2 \delta+\mu(1-\cos 2 \delta)},
$$

where $\rho_{0}$ is the crust density, $p_{w}$ is the pore pressure, $z$ is depth (downward is positive), $\delta$ is the fault dip angle, and $\mu$ is the frictional coefficient. This equation implies that the rock strength is proportional to depth $z$ (green line in Fig. 14a). Further, by assuming the plate as a rigid two-dimensional elastic plane ( $x$ - and $z$-axes are the subducting direction and vertical direction, respectively), the vertical distribution of the bending stress along the dip direction $\sigma_{x x}(z)$ is approximated as (e.g., Turcotte and Schubert 2002; Craig et al. 2014; Hunter and Watts 2016)

$$
\sigma_{x x}(z)=-\frac{E C}{1-v^{2}}\left(z-z_{0}\right),
$$

where $E$ is the Young's modulus, $C$ is the curvature of plate bending, $v$ is the Poisson's ratio, and $z_{0}$ is the 


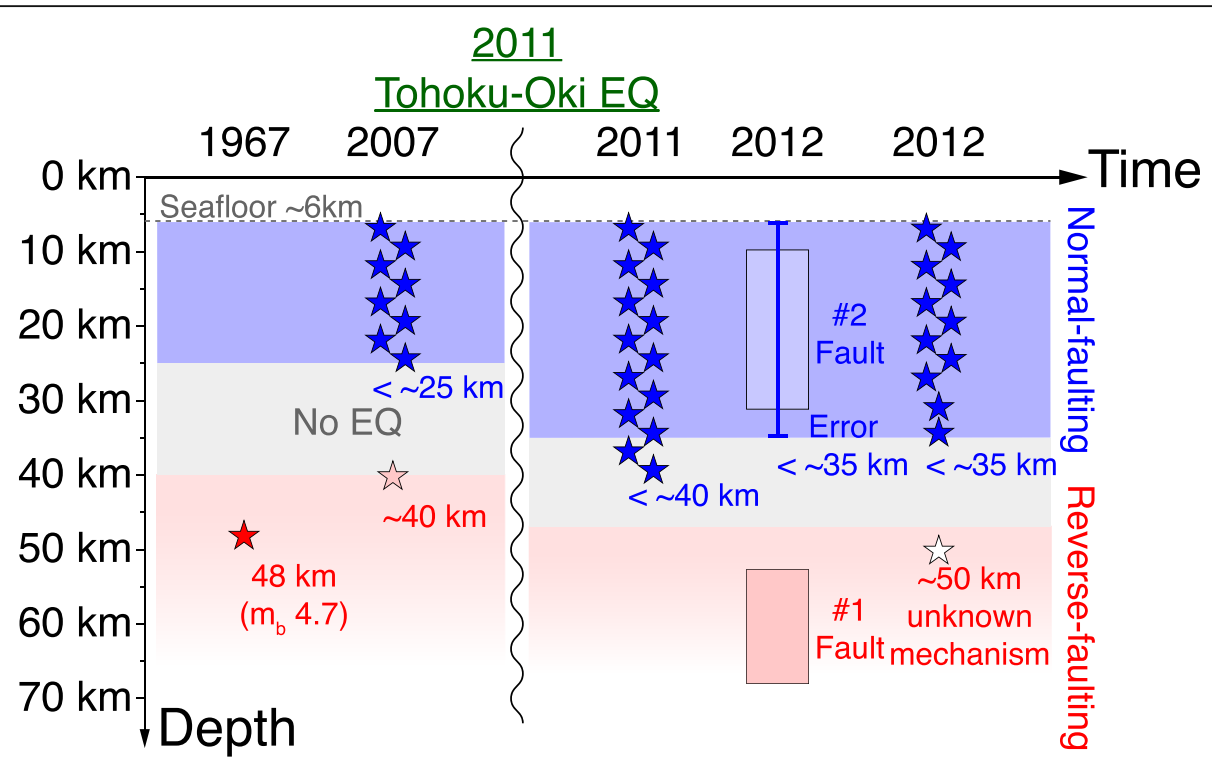

Fig. 13 Schematic representation of the vertical-temporal change of seismicity in the outer-rise region. Blue and red stars denote the normalfaulting and reverse-faulting small seismicity shown by previous studies (Seno and Gonzalez 1987; Hino et al. 2009; Obana et al. 2012, 2014, 2015). Note that the aftershocks occurred around the Mw 7.6 outer-rise $\sim 40 \mathrm{~min}$ after the Tohoku-Oki earthquake (Obana et al. 2012) are located 60 $\mathrm{km}$ east from the focal area of the 2012 doublet earthquake

stress-neutral depth (tensile stress is positive, blue line in Fig. 14a).

At a shallower portion of the plate, where the bending stress exceeds the brittle strength (the blue background area in Fig. 14a), the rock cannot remain elastic and the stress is released, or the rock yields, leading to shallow normal-faulting earthquakes. In contrast, elastic behavior is expected in the depth range where the bending stress does not exceed strength; the range is termed the elastic core (e.g., Craig et al. 2014; Hunter and Watts 2016). The actual deviatoric stress profile within the plate is represented by the red solid line in Fig. 14a. The top of

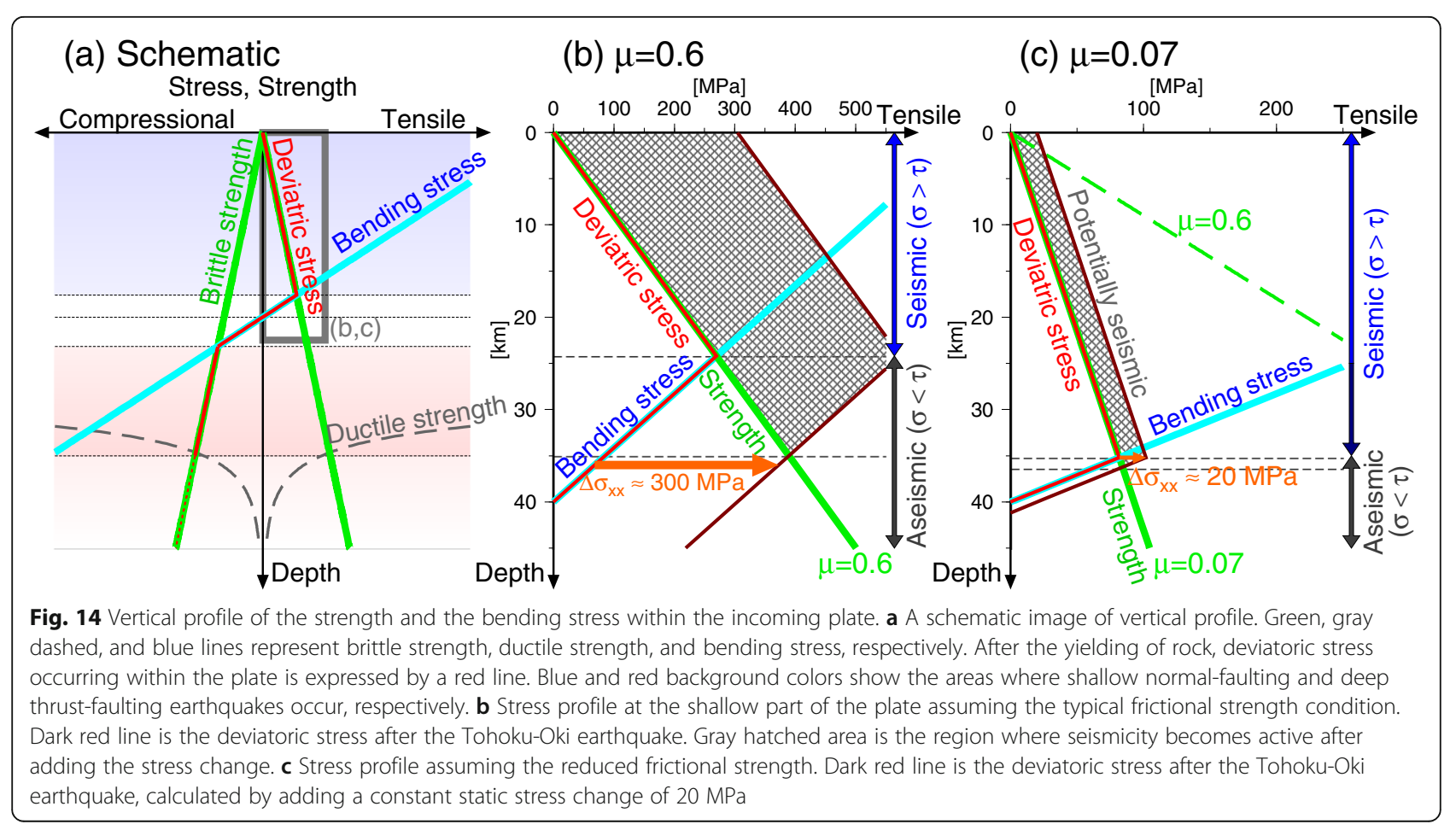


the aseismic elastic core, or the bottom of the vertical range of the normal-faulting seismicity, can be defined as a depth where the bending stress and the frictional strength are equal. As the top of the elastic core is present at a depth of $\sim 30-35 \mathrm{~km}$ and the top of the reverse-faulting seismicity (the bottom of the elastic core) at $\sim 45 \mathrm{~km}$, the stress-neutral plane is expected to be located in the depth range between $30-35$ and 45 $\mathrm{km}$. This depth range is almost consistent with the depths where fault mechanisms flip from the shallow normal-faulting to the deep thrust-faulting mechanisms, near the trench axis off NE Japan ( $25-40 \mathrm{~km}$, Gamage et al. 2009; Koga et al. 2012).

We compare the vertical profiles of the brittle strength and bending stress. Assuming $E=80 \mathrm{GPa}$ and $v=0.25$, and $C=2 \times 10^{-7} \mathrm{~m}^{-1}$ (McNutt and Menard 1982), $d \sigma_{x x} d d z$ $=E C /\left(1-v^{2}\right)$ is $\sim 15 \mathrm{MPa} / \mathrm{km}$. Assuming the hydrostatic pressure condition $p_{w}=\rho_{w} g_{0} z\left(\rho_{w}=1030 \mathrm{~kg} / \mathrm{m}^{3}\right.$, seawater density) and $\rho_{0}=2700 \mathrm{~kg} / \mathrm{m}^{3}, \delta=50^{\circ}$, and $\mu=0.6$ (e.g., Byerlee 1978), $d \tau_{x x} / d z$ is $\sim 11 \mathrm{MPa} / \mathrm{km}$ as per Eq. (2). In this situation, assuming $z_{0}=40 \mathrm{~km}, \tau_{x x}(z)$ and $\sigma_{x x}(z)$ are equal at $z \sim 25 \mathrm{~km}$ (Fig. 14b). This is consistent with the downdip limit of normal-faulting seismicity observed before the Tohoku-Oki earthquake (Hino et al. 2009). However, considering $d \sigma_{x x} / d z=\sim 15 \mathrm{MPa} / \mathrm{km}$, the stress increment of $\sim 300 \mathrm{MPa}$ is needed to deepen the top of the elastic core from 25 to $35 \mathrm{~km}$ (orange arrow in Fig. 14b). This value is too large compared to the coseismic stress change around subevent 2 expected from the fault model of the Tohoku-Oki earthquake by Iinuma et al. (2012), $\Delta \sigma_{x x}$ $\sim 20 \mathrm{MPa}$. The expected depth change of the down-dip limit of the normal faulting seismicity is only a few $\mathrm{km}$ (Fig. 14c).

It must be considered that $\tau_{x x}(z)$ and $\sigma_{x x}(z)$ are equal at $\sim 30-35 \mathrm{~km}$ depth before the Tohoku-Oki earthquake (Fig. 14c). In order that the normal-faulting earthquakes occur at a depth of $35 \mathrm{~km}$, the brittle strength must be reduced compared to the typical frictional condition (Fig. 14b). If we assume $z_{0}=40 \pm 5 \mathrm{~km}$ (Fig. 13), the frictional coefficient of the fault around the lower end of the fault of subevent 2 is $\mu \sim 0.07 \pm 0.06$ so that $\tau_{x x}(z)$ and $\sigma_{x x}(z)$ are equal at $z=35 \mathrm{~km}$ (Fig. 14c). Even when the top of the elastic core is assumed to be at $z$ $=30 \mathrm{~km}$, the expected frictional coefficient $\mu$ is $\sim 0.2$ (Additional file 1: Figure S5). These values are much smaller than that of the typical rocks but comparable to that estimated for the other incoming plate (Craig et al. 2014).

Reduction of friction has often been reported in studies on inland earthquakes (e.g., Yoshida et al. 2018); this reduction can be attributed to the existence of the pore fluid (e.g., Bell and Nur 1978). Based on the active seismic survey in the outer-rise region of the Japan trench (e.g., Fujie et al. 2018), the significant seismic wave velocity reduction and high $V_{\mathrm{p}} / V_{\mathrm{s}}$ area were detected at the shallow part of the subducting plate $(<5 \mathrm{~km})$, which are interpreted as being the results of pore fluid penetration through the pre-existing bending faults in the shallower part of the plate (e.g., Peacock 2001). Considering these studies, it is suggested that that the strength reduction within the plate might be related to the pore fluid. Numerical modeling by Faccenda et al. (2009) demonstrated that the pore fluid can infiltrate the plate as deep as the lower limit of the normal faulting seismicity observed in this study. Cai et al. (2018) also reported the serpentinized mantle wedge associated with water infiltration into the subducting plate (down to $\sim 35 \mathrm{~km}$ ) at the Mariana subduction zone.

However, the majority of the seismicity at depths of 30$35 \mathrm{~km}$ is located around the subevent 2's fault (Fig. 9) and less in the other portions of the plate. This localization of seismicity suggests that the pore fluid, or the strength reduction, is localized within the plate, as also suggested by Faccenda et al. (2009) and Obana et al. (2019).

The activation of the normal-faulting seismicity at depths of $25-35 \mathrm{~km}$ after the Tohoku-Oki earthquake can be interpreted as follows: the plate at $25-35 \mathrm{~km}$ depths had yielded before the Tohoku-Oki earthquake, leading to intrinsically aseismic region; a stress increment by the Tohoku-Oki earthquake enhanced the horizontal tensile stress in a broad depth range near the top of the elastic core, which activates seismicity. Less normal-faulting seismicity at depths of $25-35 \mathrm{~km}$ during observation from April to June 2007 (Hino et al. 2009) may be representative of the long-term-averaged deformation. It is expected that the stressing rate due to the bending deformation is lower near the stress-neutral depth, where null-deformation is expected, than the shallowest part of the incoming oceanic plate.

On the other hand, if $E C /\left(1-v^{2}\right)$ is small, the static stress change by the Tohoku-Oki earthquake can contribute to deepening the elastic core or the lower limit of the shallow normal faulting seismicity. Supposing that the elastic core is deepened by $10 \mathrm{~km}$ due to the coseismic static stress change $\Delta \sigma_{\mathrm{xx}}$ of $\sim 20 \mathrm{MPa}$ by the Tohoku-Oki earthquake, $E C /\left(1-v^{2}\right)$ must be $\sim 0.5 \mathrm{MPa} / \mathrm{km}$, which is smaller than the typical elastic condition described above by an order of magnitude. However, it is unlikely that the Young's modulus or the plate curvature are significantly reduced by an order of magnitude even if supposing the existence of the pore fluid or estimation error of the curvature. Thus, this hypothesis seems unlikely. Although it might be possible that the $E C /\left(1-v^{2}\right)$ is small compared to that assumed in this study, its contribution to deepening the elastic core associated with the Tohoku-Oki earthquake is not highly significant.

\section{Conclusions}

In this study, we estimated the fault model of the intraplate doublet earthquake that occurred on December 7, 
2012 (subevent 1: a deep reverse-faulting earthquake; subevent 2: a shallow normal-faulting earthquake) strategically utilizing offshore tsunami, aftershocks, and the teleseismic records based on the step-by-step analysis procedure. First, the initial sea-surface height distribution was estimated by inverting the offshore tsunami records and comparing it with the seafloor deformation from the CMT mechanism. It was found that the subsidence and uplift areas were generated by subevent 2 and both subevents, respectively. Then, the fault model of each subevent was estimated based on the initial seasurface height model, using information from previous studies. As a result, the vertical extent of the fault plane of subevent 2 was obtained as $\sim 5 \mathrm{~km}$ (i.e., the seafloor) to $35 \mathrm{~km}$. Finally, we simulated the tsunami and teleseismic waveforms from the fault model, which explained the observation well.

We compared the tsunami source model obtained from the near-field tsunami data acquired at less than $200 \mathrm{~km}$ from the epicenter and that from the far-field $(>200 \mathrm{~km}$ ) data. We found that the horizontal location of the tsunami source was reasonably constrained, even from the far-field tsunami data alone. However, to constrain the finite fault model in more detail, it is necessary to use the near-field tsunami records. We also discussed the stress state within the plate and its spatiotemporal change after the 2011 Tohoku-Oki earthquake. We found that the down-dip limit of the shallow normal-faulting earthquakes was obviously deepened compared with that observed in 2007, from 25 to $35 \mathrm{~km}$. However, comparing the coseismic stress change by the Tohoku-Oki earthquake and the amount of the bending stress within the plate, the plate down to $\sim 35 \mathrm{~km}$ in depth should have already yielded before the Tohoku-Oki earthquake, and the top of the elastic core been located at $\sim 35 \mathrm{~km}$. Furthermore, as the bending stress around the top of the elastic core was much smaller than the rock strength expected from the empirical relationship, the frictional strength in the range of the normal-faulting earthquakes is expected to be significantly reduced. The significant strength reduction of the plate suggests pore fluid infiltration down to $\sim 35 \mathrm{~km}$, along the bending faults.

\section{Supplementary information}

Supplementary information accompanies this paper at https://doi.org/10. 1186/s40645-019-0313-y.

\footnotetext{
Additional file 1: Figure S1. Tsunami source model of Inazu and Saito (2014) and the stations used for their inversion analysis. Comparison between the observed and simulated tsunami waveforms at the stations near the source is also shown. Figure S2. Trade-off curve between the smoothing weight and the VR used for the inversion analysis. Figure S3. Sea-surface height changes from subevent 2 with fault dimensions changed. The left-top panel shows the distribution of the tsunami source model, and others show the sea-surface height distribution of assumed fault models. Figure S4. Result of the forward calculation of the
}

teleseismic waveforms based on the optimum fault models of (a) subevent 1 and (b) subevent 2. Figure S5. Vertical profile of the strength and the bending stress within the incoming plate, assuming the top depth of elastic core at $30 \mathrm{~km}$.

Additional file 2: Dataset S1. The TPG data used in this study.

\section{Abbreviations}

CMT: Centroid moment tensor; DART: Deep-ocean Assessment and Reporting of Tsunamis; GCMT: Global Centroid Moment Tensor; JAMSTEC: Japan Agency for Marine-Earth Science and Technology; KPG: Pressure Gauge Installed off Kushiro; PARI: Port and Airport Research Institute; PG: Pressure gauge; TPG: Pressure gauge installed by Tohoku University; VR: Variance reduction

\section{Acknowledgements}

We thank the reviewer Thorne Lay and another anonymous reviewer, as well as the editor, Frantisek Gallovic, for their reviews and insightful comments. We thank Koichiro Obana for providing aftershock data and Keisuke Yoshida for providing stress change data due to the Tohoku-Oki earthquake. We thank Eddie Bernard, Yong Wei, Science Applications International Corporation (SAIC), and JMA for providing DART data. We also thank JAMSTEC and PARI for providing the KPG and GPS buoy data, respectively. We also thank Editage (www.editage.jp) for English language editing. The figures in this paper were prepared using Generic Mapping Tools (Wessel \& Smith 1998). TK thanks Koichiro Obana and Tatsuhiko Saito for insightful discussions. Without the constructive comments and enormous encouragement from Yusaku Ohta, this paper would not have been published.

\section{Authors' contributions}

TK designed the study, analyzed the data, interpreted the results, and drafted the manuscript. $\mathrm{RH}$ contributed to fault modeling, data interpretation, and revision of the manuscript. DI contributed to tsunami modeling and revising the manuscript. SS took part in the installation and retrieval of the pressure data. All authors approved the final manuscript.

\section{Funding}

This work was supported by the research project "Research concerning Interaction between the Tokai, Tonankai and Nankai earthquakes" of the Ministry of Education, Culture, Sports, Science and Technology, Japan, by JSPS KAKENHI [Grant Numbers JP20244070, JP26000002, and JP 19K14818], and by the Sasakawa Scientific Research Grant [2019-2037] of the Japan Science Society.

\section{Availability of data and materials}

TPG data is available in Additional file. KPG data were obtained from the Submarine Cable Data Center (SCDC), JAMSTEC (http://www.jamstec.go.jp/ scdc/top_e.html). Teleseismic data were downloaded from the Data Management Center (DMC) of Incorporated Research Institutions for Seismology (IRIS) (http://ds.iris.edu/ds/nodes/dmc/tools/event/3650366). GPS buoy data were obtained by a request to PARI. The data from DART, which is jointly operated by NOAA and JMA, was provided upon request by Eddie Bernard and Yong Wei from Science Applications International Corporation (SAIC). Aftershock data was provided by Koichiro Obana.

\section{Competing interests}

The authors declare that they have no competing interests.

\section{Author details}

${ }^{1}$ National Research Institute for Earth Science and Disaster Resilience, 3-1 Tennodai, Tsukuba, Ibaraki 305-0006, Japan. ${ }^{2}$ Graduate School of Science, Tohoku University, 6-6 Aza-Aoba, Aramaki, Aoba-ku, Sendai, Miyagi 980-8578, Japan. ${ }^{3}$ Department of Marine Resources and Energy, Tokyo University of Marine Science and Technology, 4-5-7 Konan, Minato, Tokyo 108-8477, Japan. 
Received: 31 August 2019 Accepted: 13 November 2019 Published online: 26 December 2019

\section{References}

Amante C, Eakins BW (2009) ETOPO1 1 Arc-Minute Global Relief Model: Procedures, Data Sources and Analysis. National Geophysical Data Center, NOAA, Boulder, Colorado, doi:doi.org/10.7289/N5C8276M

Bell ML, Nur A (1978) Strength changes due to reservoir-induced pore pressure and stresses and application to Lake Oroville. J Geophys Res Solid Earth 83: 4469-4483. https://doi.org/10.1029/JB083iB09p04469

Bernard E, Wei Y, Tang L, Titov V (2014) Impact of near-field, deep-ocean tsunam observations on forecasting the 7 December 2012 Japanese tsunami. Pure Appl Geophys 171:3483-3491. https://doi.org/10.1007/s00024-013-0720-8

Byerlee J (1978) Friction of rocks. Pure Appl Geophys 116:615-626. https://doi. org/10.1007/BF00876528

Cai C, Wiens DA, Shen W, Eimer M (2018) Water input into the Mariana subduction zone estimated from ocean-bottom seismic data. Nature 563 : 389-392. https://doi.org/10.1038/s41586-018-0655-4

Chapple WM, Forsyth DW (1979) Earthquakes and bending of plates at trenches. J Geophys Res 84(B12):6729-6749. https://doi.org/10.1029/JB084iB12p06729

Christensen DH, Ruff LJ (1988) Seismic coupling and outer rise earthquakes. J Geophys Res Solid Earth 93:13421-13444. https://doi.org/10.1029/ JB093iB11p13421

Craig TJ, Copley A, Jackson J (2014) A reassessment of outer-rise seismicity and its implications for the mechanics of oceanic lithosphere. Geophys J Int 197 : 63-89. https://doi.org/10.1093/gii/ggu013

Dmowska R, Lovison LC (1988) Intermediate-term seismic precursors for some coupled subduction zones. Pure Appl Geophys 126:643-664. https://doi.org/ 10.1007/BF00879013

Ekström G, Nettles M, Dziewoński AM (2012) The global CMT project 2004-2010: Centroid-moment tensors for 13,017 earthquakes. Phys Earth Planet Inter 200-201:1-9. https://doi.org/10.1016/j.pepi.2012.04.002

Faccenda M, Gerya TV, Burlini L (2009) Deep slab hydration induced by bendingrelated variations in tectonic pressure. Nat Geosci 2:790-793. https://doi.org/ 10.1038/ngeo656

Fujie G, Kodaira S, Kaiho Y, Yamamoto Y, Takahashi T, Miura S, Yamada T (2018) Controlling factor of incoming plate hydration at the north-western Pacific margin. Nat Commun 9:3844. https://doi.org/10.1038/s41467-018-06320-z

Gamage SSN, Umino N, Hasegawa A, Kirby SH (2009) Offshore double-planed shallow seismic zone in the NE Japan forearc region revealed by SP depth phases recorded by regional networks. Geophys J Int 178:195-214. https:// doi.org/10.1111/j.1365-246X.2009.04048.x

Harada T, Murotani S, Satake K (2013) A deep outer-rise reverse-fault earthquake immediately triggered a shallow normal-fault earthquake: The 7 December 2012 off-Sanriku earthquake ( $M_{w}$ 7.3). Geophys Res Lett 40:4214-4219. https://doi.org/10.1002/grl.50808

Hino R, Azuma R, Ito Y, Yamamoto Y, Suzuki K, Tsushima H, Suzuki S, Miyashita M, Tomori T, Arizono M, Tange G (2009) Insight into complex rupturing of the immature bending normal fault in the outer slope of the Japan Trench from aftershocks of the 2005 Sanriku earthquake ( $M w=7.0)$ located by ocean bottom seismometry. Geochem, Geophys Geosyst 10:Q07018. doi: 10.1029/ 2009GC002415

Hino R, Inazu D, Ohta Y, Ito Y, Suzuki S, linuma T, Osada Y, Kido M, Fujimoto H, Kaneda Y (2014) Was the 2011 Tohoku-Oki earthquake preceded by aseismic preslip? Examination of seafloor vertical deformation data near the epicenter. Mar Geophys Res 35:181-190. https://doi.org/10.1007/s11001-013-9208-2

Hirata K, Aoyagi M, Mikada H, Kawaguchi K, Kaiho Y, Iwase R, Morita S, Fujisawa I, Sugioka H, Mitsuzawa K, Suyehiro K, Kinoshita H, Fujiwara N (2002) Real-time geophysical measurements on the deep seafloor using submarine cable in the Southern Kurile subduction zone. IEEE J Ocean Eng 27:170-181. https:// doi.org/10.1109/JOE.2002.1002471

Hunter J, Watts AB (2016) Gravity anomalies, flexure and mantle rheology seaward of circum-Pacific trenches. Geophys J Int 207:288-316. https://doi. org/10.1093/gji/ggw275

linuma T, Hino R, Kido M, Inazu D, Osada Y, Ito Y, Ohzono M, Tsushima H, Suzuki S, Fujimoto H, Miura S (2012) Coseismic slip distribution of the 2011 off the Pacific Coast of Tohoku Earthquake (M9.0) refined by means of seafloor geodetic data. J Geophys Res 117:B07409. doi: https://doi.org/10.1029/ 2012JB009186

Inazu D, Saito T (2014) Two subevents across the Japan Trench during the 7 December 2012 off Tohoku earthquake (Mw 7.3) inferred from offshore tsunami records. J Geophys Res Solid Earth 119:5800-5813. https://doi.org/10. 1002/2013JB010892

Ito A, Fujie G, Miura S, Kodaira S, Kaneda Y, Hino R (2005) Bending of the subducting oceanic plate and its implication for rupture propagation of large interplate earthquakes off Miyagi, Japan, in the Japan Trench subduction zone. Geophys Res Lett 32:L05310. https://doi.org/10.1029/2004GL022307

Kato T, Terada Y, Ito K, Hattori R, Abe T, Miyake T, Koshimura S, Nagai T (2005) Tsunami due to the 2004 September 5th off the Kii peninsula earthquake, Japan, recorded by a new GPS buoy. Earth Planets Space 57:297-301. https:// doi.org/10.1186/BF03352566

Kikuchi M, Kanamori H (1991) Inversion of complex body waves-III. Bull Seismol Soc Am 81:2335-2350

Kikuchi M, Kanamori H (2003) Note on teleseismic body-wave inversion program. http://www.eri.u-tokyo.ac.jp/ETAL/KIKUCHI/.

Koga S, Ito Y, Hino R, Shinohara M, Umino N (2012) Focal mechanisms of small earthquakes within the Pacific Plate near the Japan Trench. Zisin 2(64):75-90 (in Japanese with English abstract). https://doi.org/10.4294/zisin.64.75

Kubota T, Hino R, Inazu D, Ito Y, linuma T (2015) Complicated rupture process of the Mw 7.0 intraslab strike-slip earthquake in the Tohoku region on 10 July 2011 revealed by near-field pressure records. Geophys Res Lett 42:9733-9739. https://doi.org/10.1002/2015GL066101

Kubota T, Hino R, Inazu D, Ito Y, linuma T, Ohta Y, Suzuki S, Suzuki K (2017a) Coseismic slip model of offshore moderate interplate earthquakes on March 9, 2011 in Tohoku using tsunami waveforms. Earth Planet Sci Lett 458:241251. https://doi.org/10.1016/j.epsl.2016.10.047

Kubota T, Saito T, Ito Y, Kaneko Y, Wallace LM, Suzuki S, Hino R, Henrys S (2018b) Using tsunami waves reflected at the coast to improve offshore earthquake source parameters: Application to the 2016 Mw 7.1 Te Araroa earthquake, New Zealand. J Geophys Res Solid Earth 123:8767-8779. https://doi.org/10. 1029/2018JB015832

Kubota T, Saito T, Suzuki W, Hino R (2017b) Estimation of seismic centroid moment tensor using ocean bottom pressure gauges as seismometers. Geophys Res Lett 44:10907-10915. https://doi.org/10.1002/2017GL075386

Kubota T, Suzuki W, Nakamura T, Chikasada NY, Aoi S, Takahashi N, Hino R (2018a) Tsunami source inversion using time-derivative waveform of offshore pressure records to reduce effects of non-tsunami components. Geophys J Int 215:1200-1214. https://doi.org/10.1093/gji/ggy345

Lay T, Duputel Z, Ye L, Kanamori H (2013) The December 7, 2012 Japan Trench intraplate doublet $(\mathrm{Mw} 7.2,7.1)$ and interactions between near-trench intraplate thrust and normal faulting. Phys Earth Planet Inter 220:73-78. https://doi.org/10.1016/j.pepi.2013.04.009

Matsumoto K, Takanezawa T, Ooe M (2000) Ocean tide models developed by assimilating TOPEX/POSEIDON altimeter data into hydrodynamical model: A global model and a regional model around Japan. J Oceanogr 56:567-581. https://doi.org/10.1023/A:1011157212596

McNutt MK, Menard HW (1982) Constraints on yield strength in the oceanic lithosphere derived from observations of flexure. Geophys J Int 71:363-394. https://doi.org/10.1111/j.1365-246X.1982.tb05994.x

Obana K, Fujie G, Kodaira S, Takahashi T, Yamamoto Y, Sato T, Yamashita M, Nakamura Y, Miura S (2015). SeismSSicity and structure of the incoming Pacific plate subducting into the Japan Trench off Miyagi. Abstract T43G-01 presented at 2015 AGU Fall Meeting, San Francisco, CA, 14-18 Dec 2015.

Obana K, Fujie G, Takahashi T, Yamamoto Y, Nakamura Y, Kodaira S, Takahashi N, Kaneda Y, Shinohara M (2012) Normal-faulting earthquakes beneath the outer slope of the Japan Trench after the 2011 Tohoku earthquake: Implications for the stress regime in the incoming Pacific plate. Geophys Res Lett 39:L00G24. doi: https://doi.org/10.1029/2011GL050399

Obana K, Fujie G, Takahashi T, Yamamoto Y, Tonegawa T, Miura S, Kodaira S (2019) Seismic velocity structure and its implications for oceanic mantle hydration in the trench-outer rise of the Japan Trench. Geophys J Int 16291642. doi: https://doi.org/10.1093/gji/ggz099

Obana K, Kodaira S, Nakamura Y, Sato T, Fujie G, Takahashi T, Yamamoto Y (2014) Aftershocks of the December 7, 2012 intraplate doublet near the Japan Trench axis. Earth, Planets Sp 66:24. https://doi.org/10.1186/1880-5981-66-24

Okada Y (1992) Internal deformation due to shear and tensile faults in a halfspace. Bull Seismol Soc Am 82:1018-1040

Peacock SM (2001) Are the lower planes of double seismic zones caused by serpentine dehydration in subducting oceanic mantle? Geology 29:299-302. https://doi.org/10.1130/0091-7613(2001)029<0299:ATLPOD>2.0.CO;2

Saito M (1978) An automatic design algorithm for band selective recursive digital filters. Butsuri Tanko 31:112-135 (in Japanese) 
Saito T (2019) Tsunami Generation and Propagation. Springer Japan, Tokyo. https://doi.org/10.1007/978-4-431-56850-6

Scholz CH (1988) The brittle-plastic transition and the depth of seismic faulting. Geol Rundschau 77:319-328. https://doi.org/10.1007/BF01848693

Seno T, Gonzalez DG (1987) Faulting caused by earthquakes beneath the outer slope of the Japan Trench. J Phys Earth 35:381-407. https://doi.org/10.4294/ jpe1952.35.381

Tsushima H, Hino R, Tanioka Y et al (2012) Tsunami waveform inversion incorporating permanent seafloor deformation and its application to tsunami forecasting. J Geophys Res 117:B03311. https://doi.org/10.1029/2011JB008877

Turcotte DL, Schubert G (2002) Geodynamics, 2nd ed. Cambridge University Press. https://doi.org/10.1017/CBO9780511807442

Wallace LM, Araki E, Saffer D et al (2016) Near-field observations of an offshore Mw 6.0 earthquake from an integrated seafloor and subseafloor monitoring network at the Nankai Trough, southwest Japan. J Geophys Res Solid Earth 121:8338-8351. https://doi.org/10.1002/2016JB013417

Wessel P, Smith WHF (1998) New, improved version of generic mapping tools released. Eos, Trans Am Geophys Union 79:579. https://doi.org/10.1029/ $98 \mathrm{EO} 00426$

Yoshida K, Hasegawa A, Yoshida T, Matsuzawa T (2018) Heterogeneities in stress and strength in Tohoku and its relationship with earthquake sequences triggered by the 2011 M9 Tohoku-Oki earthquake. Pure Appl Geophys. https://doi.org/10.1007/s00024-018-2073-9

\section{Publisher's Note}

Springer Nature remains neutral with regard to jurisdictional claims in published maps and institutional affiliations.

\section{Submit your manuscript to a SpringerOpen ${ }^{\circ}$ journal and benefit from:}

- Convenient online submission

- Rigorous peer review

- Open access: articles freely available online

High visibility within the field

- Retaining the copyright to your article

Submit your next manuscript at $\boldsymbol{\nabla}$ springeropen.com 